\title{
OMPS LP Version 2.0 multi-wavelength aerosol extinction coefficient retrieval algorithm
}

\author{
Ghassan Taha $^{1,2}$, Robert Loughman ${ }^{3}$, Tong $\mathrm{Zhu}^{4}$, Larry Thomason ${ }^{5}$, Jayanta Kar ${ }^{5,6}$, Landon Rieger ${ }^{7}$, and \\ Adam Bourassa ${ }^{7}$ \\ ${ }^{1}$ Universities Space Research Association (USRA), Greenbelt, MD, USA \\ ${ }^{2}$ NASA Goddard Space Flight Center, Greenbelt, MD, USA \\ ${ }^{3}$ Department of Atmospheric and Planetary Sciences, Hampton University, Hampton, VA, USA \\ ${ }^{4}$ Science Systems and Applications Inc., Greenbelt, MD, USA \\ ${ }^{5}$ Science Directorate, NASA Langley Research Center, Hampton, VA, USA \\ ${ }^{6}$ Science Systems and Applications Inc., Hampton, VA, USA \\ ${ }^{7}$ Institute of Space and Atmospheric Studies, University of Saskatchewan, Saskatoon, Saskatchewan, Canada
}

Correspondence: Ghassan Taha (ghassan.taha@nasa.gov)

Received: 13 August 2020 - Discussion started: 4 September 2020

Revised: 1 December 2020 - Accepted: 30 December 2020 - Published: 10 February 2021

\begin{abstract}
The OMPS Limb Profiler (LP) instrument is designed to provide high-vertical-resolution ozone and aerosol profiles from measurements of the scattered solar radiation in the $290-1000 \mathrm{~nm}$ spectral range. It collected its first Earth limb measurement on 10 January 2012 and continues to provide daily global measurements of ozone and aerosol profiles from the cloud top up to 60 and $40 \mathrm{~km}$, respectively. The relatively high vertical and spatial sampling allow detection and tracking of sporadic events when aerosol particles are injected into the stratosphere, such as volcanic eruptions or pyrocumulonimbus (PyroCb) events. In this paper we discuss the newly released Version 2.0 OMPS multi-wavelength aerosol extinction coefficient retrieval algorithm. The algorithm now produces aerosol extinction profiles at 510, 600, 674, 745, 869 and $997 \mathrm{~nm}$ wavelengths. The OMPS LP Version 2.0 data products are compared to the SAGE III/ISS, OSIRIS and CALIPSO missions and shown to be of good quality and suitable for scientific studies. The comparison shows significant improvements in the OMPS LP retrieval performance in the Southern Hemisphere (SH) and at lower altitudes. These improvements arise from use of the longer wavelengths, in contrast with the V1.0 and V1.5 OMPS aerosol retrieval algorithms, which used radiances only at $675 \mathrm{~nm}$ and therefore had limited sensitivity in those regions. In particular, the extinction coefficients at 745,869 and $997 \mathrm{~nm}$ are shown to be the most accurate, with relative
\end{abstract}

accuracies and precisions close to $10 \%$ and $15 \%$, respectively, while the $675 \mathrm{~nm}$ relative accuracy and precision are on the order of $20 \%$. The $510 \mathrm{~nm}$ extinction coefficient is shown to have limited accuracy in the SH and is only recommended for use between $20-24 \mathrm{~km}$ and only in the Northern Hemisphere. The V2.0 retrieval algorithm has been applied to the complete set of OMPS LP measurements, and the new dataset is publicly available.

\section{Introduction}

\subsection{The importance of stratospheric aerosol measurements}

Observations of the stratospheric aerosol layer were first provided by Junge et al. (1961) using balloon-borne measurements, showing a layer extending from 15 to $25 \mathrm{~km}$ altitude with a peak at $20 \mathrm{~km}$. Further measurements established that the main composition of the aerosol in this layer is $75 \%$ sulfuric acid and $25 \%$ water (SPARC, 2006; Deshler, 2008). The stratospheric aerosol budget is dominated by natural sources, where volcanic injections of $\mathrm{SO}_{2}$ and aerosol directly into the lower stratosphere stand out as the largest source over the past decades. Carbonyl sulfide (OCS) makes the second largest contribution to the aerosol layer. These 
sulfur species originate at the Earth's surface in a variety of reduced forms (including $\mathrm{CS}_{2}$, DMS and $\mathrm{H}_{2} \mathrm{~S}$ ) before oxidation in the atmosphere (Kremser et al., 2016). Other sources of stratospheric aerosol include the transport of tropospheric aerosol across the tropical tropopause through large convective systems such as the Asian monsoon (Vernier et al., 2011a; Thomason and Vernier, 2013). In recent years, there has been evidence that pyrocumulonimbus (PyroCb) events during large wildfires can inject smoke aerosol into the stratosphere, which can be comparable to volcanic aerosol injections in terms of impact on the stratosphere (Fromm et al., 2010; Peterson et al., 2018; Yu et al. 2019; Torres et al., 2020).

Stratospheric aerosols can have a direct impact on Earth's climate system by affecting its radiative balance, and they also play an important role in the chemical and dynamical processes related to ozone destruction in the stratosphere (Hofmann and Solomon, 1989; Solomon, 1999; Zhu et al., 2018). Powerful volcanic eruptions such as Mount Pinatubo in 1991 can increase the stratospheric sulfur burden by several orders of magnitude over the pre-eruption levels, which can last for several years and lead to stratospheric warming and tropospheric cooling (Robock, 2000; Deshler, 2008). A volcanic eruption like Pinatubo can also lead to cooling of the surface temperature on the order of a few tenths of a degree (Robock and Mao, 1995). It was also shown that the background stratospheric aerosol layer is persistently variable, modulated by weaker volcanic eruptions, thus affecting the global surface temperature (Solomon et al., 2011; Vernier et al., 2011b). Furthermore, Santer et al. (2014) identify statistically significant anti-correlations between observations of stratospheric aerosol optical depth and satellite-based estimates of tropospheric temperature, and they show that climate model simulations without the effects of early 21 st century volcanic eruptions overestimate the tropospheric warming observed since 1998. Other investigations confirm that early 21 st century volcanic eruptions are one of several factors that affect the decreased warming observed during that period (relative to expectations based on continued growth of the greenhouse gases in the atmosphere) (Schmidt et al., 2014; Medhaug et al., 2017). Stratospheric aerosol has also been used as a tracer to study stratospheric dynamics (Trepte and Hitchman, 1992; Jaeger, 2005; Fairlie et al., 2014). Over the past few years, there has been a rising interest in the geoengineering concept for solar radiation management, by injecting aerosol into the stratosphere (Rasch et al., 2008), for which a basic understanding of the present stratospheric aerosol layer is essential. A review paper by Kremser et al. (2016) concluded that it is critical to maintain continuous observational records to detect unpredictable events (like large volcanic eruptions) or unexpected developments (such as non-volcanic processes like strong PyroCb events that result in changes in stratospheric aerosol levels), noting that observations are critical for testing the reliability of climate models.

\subsection{Overview of stratospheric aerosol measurement types}

A comprehensive review of the wide variety of stratospheric aerosol measurements is outside the scope of this study. (The interested reader should refer to Sect. 4 of Kremser et al., 2016, for example.) This section will briefly name some key types of measurements that are useful for determining various properties of stratospheric aerosols and highlight some advantages and disadvantages of each technique. This overview will focus primarily on the space-based remote sensing methods that are discussed further in Sects. 35 , especially those that are used directly to assess the performance of the OMPS LP aerosol extinction retrieval.

\subsubsection{In situ and ground-based measurements}

In situ measurements mainly provide information about the stratospheric aerosol size distribution, from which moments (such as surface area density and volume density) can be derived. These instruments directly sample stratospheric air, using a balloon-borne or aircraft platform. Examples include the optical particle counters (OPCs; Hofmann and Deshler, 1991; Jaeger and Deshler, 2002), the airborne focused cavity aerosol spectrometer (FCAS; Jonsson et al., 1995), and the nucleation-mode aerosol size spectrometer (NMASS; Brock et al., 2000). Size information can be obtained for particles in the size range $0.05-10 \mu \mathrm{m}$, depending on the particular instrument. In situ measurements can provide higher temporal and spatial sampling than other techniques during a measurement campaign. But the cost and effort associated with such a campaign limit this method to intensive case studies, rather than providing broad temporal and spatial coverage.

Ground-based lidars also make measurements of stratospheric aerosols (Poole and McCormick, 1988; Chouza et al., 2020). In this case, the signal consists of photons backscattered by stratospheric aerosols, and therefore the measurements provide the backscattering coefficient of the particles. This is typically converted into an aerosol extinction coefficient, using an assumed "lidar ratio" as the conversion factor. The signal-to-noise ratio of a single lidar measurement is generally low, which requires a combination of many individual shots to produce useful retrievals. Ground-based lidars are typically stationary, so they provide information at just one location, but they can provide high temporal sampling and good vertical resolution.

\subsubsection{Space-based occultation measurements}

The primary space-based method for characterizing stratospheric aerosol is the occultation method, in which photons emitted by a bright source of radiation are transmitted through the atmosphere as the source rises or sets through the atmosphere (as viewed by the instrument). These lineof-sight transmission profiles are then converted into vertical 
profiles of extinction coefficient for the various atmospheric constituents, including aerosol extinction coefficient. The transmission measurement is essentially "self-calibrating," and this fact (combined with the high signal-to-noise ratio provided by a bright radiation source) leads to retrievals with high precision and accuracy. However, the locations and frequency of occultation events are entirely determined by the orbit of the instrument, which limits the coverage that can be achieved.

Most occultation measurements for stratospheric aerosol studies use solar occultation (with the sun as the source of photons). Examples of this technique include the Stratospheric Aerosol Measurement (SAM II; McCormick et al., 1982), the Stratospheric Aerosol and Gas Experiment (SAGE II; Chu et al., 1989) and SAGE III (Thomason and Taha, 2003), Polar Ozone and Aerosol Measurement (POAM II and III; Lumpe et al., 2002), the Halogen Occultation Experiment (HALOE; Hervig et al., 1996), the Improved Limb Atmospheric Spectrometer (ILAS I and II; Hayashida et al., 2000; Saitoh et al., 2006), and the Measurement of Aerosol Extinction in the Stratosphere and Troposphere Retrieved by Occultation (MAESTRO; McElroy et al., 2007; Sioris et al., 2010). Aerosol extinction profiles were also measured by the stellar occultation instrument Global Ozone Monitoring by Occultation of Stars (GOMOS; Vanhellemont et al., 2010). The particular solar occultation instrument used in this study (the SAGE III instrument on the ISS) is described further in Sect. 3.1.

\subsubsection{Space-based limb scattering measurements}

In recent years, several limb scattering (LS) measurements have become available, including SAGE III limb (Rault and Taha, 2007), Optical Spectrograph and InfraRed Imager System (OSIRIS; Llewellyn et al., 2004; Bourassa et al., 2007), SpectroMeter for Atmospheric CHartographY (SCIAMACHY; Taha et al., 2011; von Savigny et al., 2015; Malinina et al., 2018) and OMPS LP (Gorkavyi et al., 2013; Rault and Loughman, 2013). These instruments measure the radiance scattered by the limb of the atmosphere. The strength of the stratospheric aerosol signal in these radiances depends on several aerosol properties, including the aerosol refractive index, shape, size and number density. These properties affect both the aerosol phase function and aerosol extinction coefficient, both of which influence the aerosol signal present in the measured limb radiance.

This study evaluates the OMPS LP V2.0 aerosol extinction retrieval algorithm, which estimates the aerosol extinction coefficient based on the measured LS radiance as described in Sect. 2.2. The resulting extinction coefficients are compared to the OSIRIS aerosol extinction product, which is described further in Sect. 3.2.

\subsubsection{Space-based lidar measurements}

Spaceborne backscatter lidar measurements by CloudAerosol Lidar and Infrared Pathfinder Satellite Observation (CALIPSO) are also used to explore the stratospheric aerosol layer (Thomason et al., 2007a; Vernier et al., 2009; Kar et al., 2019). The description given in Sect. 1.2.1 for ground-based lidars generally applies to the spaceborne lidars as well. The main difference is that an orbiting lidar provides the additional advantage of mobility (near global coverage in the case of CALIPSO). The spaceborne CALIPSO lidar instrument is used in this study and is described further in Sect. 3.3.

\subsubsection{Summary of available measurements}

In 2017, accurate solar occultation measurements of stratospheric aerosols resumed after the deployment of SAGE III on the International Space Station (ISS; Cisewski et al., 2014). Combined with the ongoing OSIRIS and CALIPSO missions, we now have coincident stratospheric aerosol measurements from several space-based platforms. The structure of this paper is as follows: in Sect. 2 we provide a brief description of the OMPS LP instrument and V2.0 algorithm changes. The correlative satellite aerosol measurements are described further in Sect. 3. Section 4 describes the validation methodology. The comparison results are shown in Sect. 5, followed by conclusions in Sect. 6.

\section{OMPS LP measurements and algorithm description}

\subsection{Instrument review}

The OMPS LP sensor images the Earth limb by pointing aft along the spacecraft flight path to measure the sunlit portion of the globe without directly observing the sun. The sensor employs three vertical slits separated horizontally to provide near-global coverage in 3-4 d and more than 7000 profiles a day. The instrument measures limb scattering radiance at the $290-1000 \mathrm{~nm}$ wavelength range and the 0$80 \mathrm{~km}$ altitude range. The instrument is installed in a fixed orientation relative to the spacecraft, which flies in a sunsynchronous ascending orbit with 13:30 Equator crossing time. As a result, the observed single-scattering angle (SSA) varies along the orbit, where the Northern Hemisphere $(\mathrm{NH})$ observations correspond to forward-scattered solar radiation, and the Southern Hemisphere ( $\mathrm{SH}$ ) observations correspond to backscattered radiation. Therefore, the aerosol scattering signal is much larger in $\mathrm{NH}$ than in the $\mathrm{SH}$, resulting in a sampling of the aerosol phase function magnitude varying by a factor of 50 over the course of OMPS orbit (Loughman et al., 2018). OMPS LP is scheduled to fly on the NOAA JPSS-2, JPSS-3 and JPSS-4 satellites, to extend the stratospheric aerosol measurements into the next couple of decades. (These satellite launches are currently targeted for 2022, 2026 and 2031, respectively.) 


\subsection{OMPS LP V2.0 algorithm improvement}

The Version 2.0 (V2.0) OMPS LP aerosol extinction retrieval algorithm builds upon the Version 1.0 (V1.0) and Version 1.5 (V1.5) algorithms, which were described in Sect. 4 of Loughman et al. (2018) and Sects. 2 and 3 of Chen et al. (2018), respectively. We therefore begin by briefly reviewing the V1.0 and V1.5 algorithms in Sect. 2.2.1 and defining the key variables used. This is followed by Sect. 2.2.2, which details the algorithm updates made to produce V2.0.

\subsubsection{Review of the V1.0 and V1.5 OMPS LP algorithms}

Unlike solar occultation, limb scattering retrievals require complex forward model calculations, and the aerosol retrieval in particular requires assumptions of aerosol refractive index and size parameters. Previous versions of the OMPS LP aerosol retrieval algorithm were mainly designed for minimizing the errors of ozone profiles and level-1 radiance diagnostics. The V1.0 and V1.5 algorithms use OMPS LP radiance measurements, $\boldsymbol{I}_{\mathrm{m}}(\lambda, h)$, for a range of tangent heights, $h$, at a single wavelength $(\lambda=675 \mathrm{~nm})$ to estimate the aerosol extinction profile. This wavelength was selected to be near the Chappuis band that is used to retrieve the ozone profile in the visible region, for which the OMPS LP radiances are best characterized. The algorithm assesses the measurements by comparison to two analogous sets of calculated radiances, $\boldsymbol{I}_{c}(\lambda, h)$ and $\boldsymbol{I}_{c_{0}}(\lambda, h)$. These calculated radiance profiles are generated by the Gauss-Seidel limb scattering (GSLS) radiative transfer model (RTM) (Loughman et al., 2004) for the same viewing and solar illumination conditions that existed when $\boldsymbol{I}_{\mathrm{m}}(\lambda, h)$ was measured. The model atmospheres used (described further below) are identical for these two calculations, with one exception: in the case of $\boldsymbol{I}_{c_{0}}(\lambda, h)$, the model atmosphere contains no aerosols, while the $\boldsymbol{I}_{c}(\lambda, h)$ model atmosphere contains the first-guess aerosol profile.

The model atmosphere consists of static atmospheric temperature and pressure profiles derived from the operational geopotential height product provided by the NASA Global Modeling and Assimilation Office (GMAO). The algorithm uses the McPeters and Labow (2012) ozone climatology and the PRATMO photochemical box model $\mathrm{NO}_{2}$ climatology (McLinden et al., 2000) to define the model atmosphere. The first-guess aerosol extinction profile, $\boldsymbol{x}_{0}$, is defined based on a single SAGE climatological profile. Aerosols are assumed to consist of spherical liquid sulfate particles $\left(75 \% \mathrm{H}_{2} \mathrm{SO}_{4}\right)$ with index of refraction $m=1.448+0 i$ (Yue and Deepak, 1983; Wang et al., 1996). In the V1.0 algorithm, the aerosol size distribution (ASD) is assumed to be a bi-modal lognormal distribution (Loughman et al., 2018); this was updated to a gamma distribution in V1.5 (Chen et al., 2018). Mie scattering theory is used to calculate the aerosol phase function based on the assumed ASD and optical properties.
The Earth's surface is modeled as a Lambertian surface (for which a fraction, $R$, of the incident downward radiation is reflected as isotropic, unpolarized upward radiance field at each point). The value of $R$ is determined by requiring that $\boldsymbol{I}_{c_{0}}(\lambda, h)=\boldsymbol{I}_{\mathrm{m}}(\lambda, h)$ at $h=40.5 \mathrm{~km}$ (Loughman et al., 2018). An approximate ozone correction is also applied to the model radiances to correct for possible ozone error, as described in Sect. 4.3 of Loughman et al. (2018). To reduce the sensitivity of the algorithm to a variety of interfering factors, the radiances are normalized with respect to tangent height $h$. The measured altitude-normalized radiance (ANR) is defined as $\rho_{\mathrm{m}}(\lambda, h)=\boldsymbol{I}_{\mathrm{m}}(\lambda, h) / \boldsymbol{I}_{\mathrm{m}}\left(\lambda, h_{\mathrm{n}}\right)$, with $h_{\mathrm{n}}$, namely the normalization tangent height, set to a value of $40.5 \mathrm{~km}$ in the V1.0 and V1.5 algorithms. The value of $h_{\mathrm{n}}$ is generally selected as a compromise between two competing interests. It should be as high as possible to minimize the atmospheric aerosol extinction at $h_{\mathrm{n}}$, but not so high that the radiance at $h_{\mathrm{n}}$ is poorly characterized (due to residual stray light contamination, low signal-to-noise ratio, etc.). Analogous expressions define $\boldsymbol{\rho}_{c}(\lambda, h)$ and $\boldsymbol{\rho}_{c_{0}}(\lambda, h)$ based on the calculated radiance profiles.

As a final step, the ANR values are combined to produce the aerosol scattering index (ASI), which serves as the measurement vector $\boldsymbol{y}$ in the retrieval. The measured ASI is defined as $\boldsymbol{y}_{\mathrm{m}}(\lambda, h)=\left[\boldsymbol{\rho}_{\mathrm{m}}(\lambda, h)-\boldsymbol{\rho}_{c_{0}}(\lambda, h)\right] / \boldsymbol{\rho}_{\mathrm{m}}(\lambda, h)$, with similar definitions for $\boldsymbol{y}_{c}(\lambda, h)$ and $\boldsymbol{y}_{c_{0}}(\lambda, h)$. Since the V1.0 and V1.5 algorithms use a single wavelength, this notation can be abbreviated to $\boldsymbol{y}_{\mathrm{m}}\left(\lambda, h_{i}\right)=\boldsymbol{y}_{i}^{m}$, with a similar abbreviation $\boldsymbol{y}_{c}\left(\lambda, h_{i}\right)=\boldsymbol{y}_{i}^{n}$ used to represent the ASI calculated based on the model atmosphere after $n$ iterations of the retrieval algorithm.

The V1.0 and V1.5 algorithms use the Chahine nonlinear relaxation method (Chahine, 1970) to derive the aerosol extinction coefficient (which represents the state vector, $\boldsymbol{x}$ ) based on the measurement vector $\boldsymbol{y}$ defined above. The state vector is updated iteratively as shown in Eq. (1):

$\boldsymbol{x}_{i}^{n+1}=\boldsymbol{x}_{i}^{n} \frac{\boldsymbol{y}_{i}^{\mathrm{m}}}{\boldsymbol{y}_{i}^{n}}=\boldsymbol{x}_{i}^{n} f_{i}^{n}$.

In this expression, $x_{i}^{n+1}$ is the state vector at altitude $z_{i}$, and $n+1$ is the number of iterations. The measurement vector $\boldsymbol{y}_{i}^{\mathrm{m}}$ is the ASI at tangent height $h=z_{i}$, while $\boldsymbol{y}_{i}^{n}$ is the calculated ASI based on the extinction profile corresponding to the $n$th iteration. As shown in Eq. (1), the retrieval creates the updated aerosol extinction coefficient estimate $x_{i}^{n+1}$ by multiplying the previous estimate, $\boldsymbol{x}_{i}^{n}$, by the factor $f_{i}^{n}$. The V1.0 algorithm constrains the value of $f_{i}^{n}$ to lie between 0.2 and 2.0 and sets the number of iterations to $N=3$. These constraints were primarily motivated by caution in the early stages of developing the aerosol extinction retrieval algorithm, when the stability of the retrieval was relatively untested. The V1.5 algorithm relaxed these constraints somewhat, using $N=4$ and allowing $f_{i}^{n}$ values between 0.2 and 3.0. 


\subsubsection{Updates made for the V2.0 OMPS LP algorithm}

Since the limb scattering radiances at visible and nearinfrared wavelengths are very sensitive to aerosol properties, the V2.0 OMPS LP aerosol algorithm is modified to include multiple wavelengths in this spectral region, similar to the SAGE III aerosol channels (Thomason and Taha, 2003). The V2.0 algorithm uses OMPS LP measurements at wavelengths $510,600,675,745,869$ and $997 \mathrm{~nm}$, selected to minimize the effect of gaseous absorption, with the exception of $600 \mathrm{~nm}$, which will be used primarily for diagnostics. Each wavelength is retrieved independently, as described in the preceding section leading to Eq. (1). Taha et al. (2011) showed that, because of its strong weighting function or Jacobian matrix, retrieving aerosol profiles at longer wavelengths can improve the quality of the profile in the Southern Hemisphere, where OMPS LP observes backscattered radiation, and extend the retrieval further down in altitude. The Jacobian matrix quantifies the changes in the radiance with respect to the aerosol extinction. Multiple wavelength aerosol measurements can also provide limited information about aerosol particle size and can be used to identify cloud presence. Notice that the $997 \mathrm{~nm}$ radiance measurements are only available after 26 November 2013.

The assumed ASD is the same in V2.0 as in V1.5, but the single first-guess aerosol extinction profile has been replaced by a first-guess climatology that varies with wavelength, latitude and season, again based on the SAGE aerosol data record. The V2.0 algorithm further relaxes the constraints that were previously applied to the Chahine iteration results: $N=5$ and $f_{i}^{n}$ has an upper bound of 10.0 and no lower bound. The V2.0 algorithm also checks for convergence after each iteration, rather than always performing the stated number of iterations: iterations end when the retrieved aerosol extinction changes by $<2 \%$ at $20 \mathrm{~km}$ or when it reaches the maximum number of iterations. The planned V2.1 release next year will use modified convergence criteria that check for multiple altitudes.

Limb scattering instruments such as OSIRIS, SCIAMACHY and OMPS LP suffer from increased stray light at increasing wavelength and altitude due in part to diminishing scattered signal (Jaross et al., 2014; Rieger et al., 2019). To reduce the stray light effect on the retrieval at longer wavelengths, $h_{\mathrm{n}}$ was lowered to $38.5 \mathrm{~km}$ in V2.0 (from the $40.5 \mathrm{~km}$ value used in previous versions). The GSLS radiative transfer model used in the V2.0 algorithm was also updated as described by Loughman et al. (2015). The main improvement associated with this change involves the use of several zeniths to calculate the multiple-scattering source function along the limb line of sight, which improves the radiance calculations near the terminator. Unlike the V1.0 and V1.5 algorithms, the V2.0 GSLS model also includes refraction in the line-of-sight calculation. The V2.0 algorithm also excludes polarization (which had been included in the V1.5 radiance calculations). The exclusion of polarization is primar-
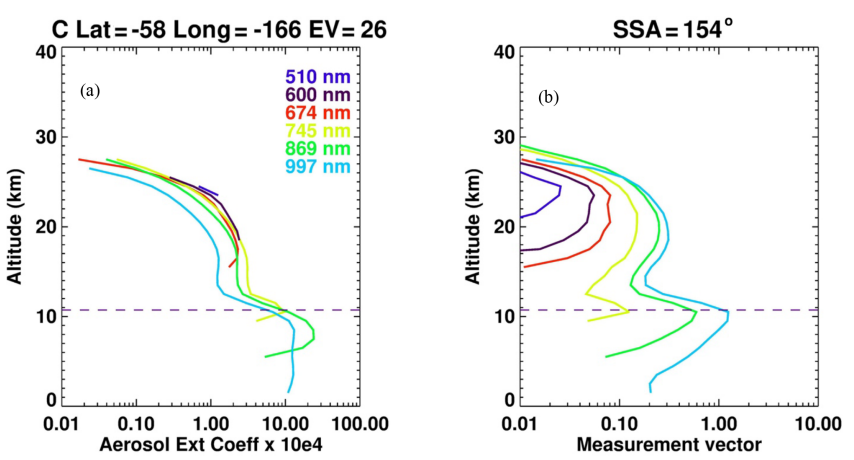

Figure 1. Panel (a) is a plot of retrieved OMPS LP aerosol extinction profiles $\left(\times 10^{4} \mathrm{~km}^{-1}\right)$ colored by wavelength for event 26 in the SH measured on 12 April 2018. Panel (b) is the aerosol scattering index (ASI) or measurement vectors $(\boldsymbol{y})$ for the same event. The dashed line is the tropopause altitude.

ily done for speed purposes: scalar (unpolarized) radiance calculations are considerably faster than their vector (polarized) counterparts, and the resulting change in $\rho_{c}(\lambda, h)$ is very small. Recent calculations performed for a RTM comparison project (Zawada et al., 2020) allow the $\boldsymbol{\rho}_{c}(\lambda, h)$ values computed by the scalar and vector versions of GSLS to be compared, for a variety of atmospheres and illumination conditions. For the relevant wavelengths $(500 \mathrm{~nm}$ and greater), these values agree to within $1 \%$ or better at $20 \mathrm{~km}$ and within $2 \%$ or better at $10 \mathrm{~km}$.

Figures 1 and 2 illustrate the contrasting effect of the scattering angle on the measurement vector and subsequent retrieved aerosol extinction profiles at different wavelengths. Figure 1 shows that at scattering angle $154^{\circ}$, wavelengths shorter than $745 \mathrm{~nm}$ have poor sensitivity to aerosol, which limits the accuracy and altitude range of the OMPS LP SH aerosol retrieval. In contrast, the longer wavelengths show high sensitivity to aerosol, thus improving the retrieval significantly at lower altitudes. Notice that the cloud at $10.5 \mathrm{~km}$ is only observed by the longer wavelengths. Figure 2 illustrates the strong sensitivity of all six wavelengths to aerosol when the scattering angle is small. In the NH, the OMPS LP measurement vector for all wavelengths is positive for all altitudes, and the aerosol retrieval quality does not vary significantly with wavelength. Notice that all retrieved aerosol wavelengths can detect the cloud layer evident as enhanced extinction near $10.5 \mathrm{~km}$.

\section{Correlative aerosol measurements}

\subsection{SAGE III/ISS}

The SAGE series of instruments started with the Stratospheric Aerosol Monitor (SAM) in 1975, SAM II in 1978 (McCormick et al., 1982), SAGE I in 1979, SAGE II (Chu et al., 1989) in 1984 and SAGE III Meteor 3M (M3M; Thoma- 

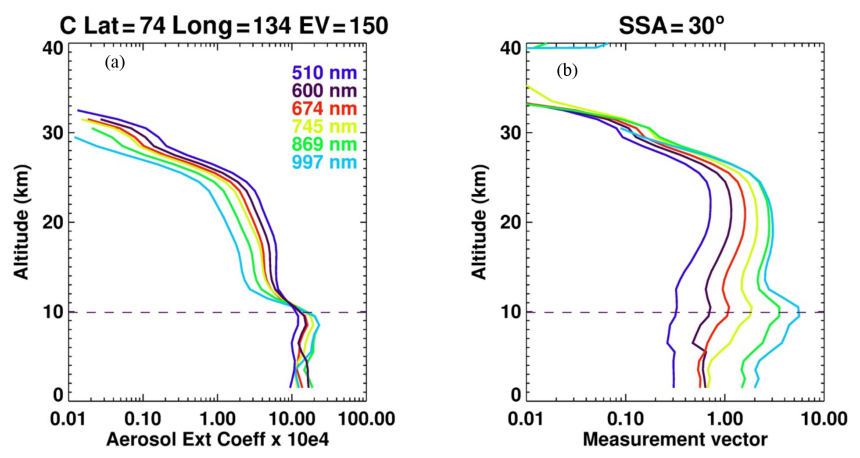

found mean differences of less than $10 \%$ in the tropics to mid-latitudes, with larger biases at higher latitudes and at altitudes outside the main aerosol layer.

More recently, the V7 OSIRIS retrieval was introduced, which combines information from measurements at 470 , 675,750 and $805 \mathrm{~nm}$ to produce multi-wavelength aerosol extinction retrievals. The expanded wavelength usage reduces biases caused by measurement geometry and improves the retrieval coverage and quality in the upper troposphere and lower stratosphere (UT-LS) region. The V7 algorithm also uses a modified version of the Chen et al. (2016) cloud detection algorithm (for polar stratospheric cloud (PSC) detection and general cloud screening). Rieger et al. (2019) report agreement at the $10 \%$ level between SAGE II and the Version 7 OSIRIS retrieval, with exceptions at high altitudes, son and Taha, 2003) in 2001, spanning over 26 years. On 19 February 2017, SAGE III was launched to the International Space Station (ISS) to resume the SAGE series of measurements. It provides high-resolution vertical profiles of aerosol extinction at multiple wavelengths; the molecular densities of ozone, nitrogen dioxide and water vapor; and profiles of temperature, pressure and cloud presence. The aerosol extinction is computed as a residual after accounting for Rayleigh scattering and gaseous absorption, and thus, the retrieval makes no prior assumptions of the aerosol size or phase function. However, the technique is limited in coverage and number of profiles, to typically about 30 per day. The SAGE III/ISS retrieval algorithm is essentially the same as its predecessor on the Meteor 3M platform. The quality of the SAGE III on Meteor 3M aerosol data was evaluated by Thomason and Taha (2003) and Thomason et al. (2007b, 2010). These studies found that the aerosol extinction measurements' accuracy and precision are on the order of $10 \%$ between 15 and $25 \mathrm{~km}$, with the exception of 601 and $675 \mathrm{~nm}$ above $20 \mathrm{~km}$, which exhibit substantial bias that was caused by the ozone clearing. A recent study by Wang et al. (2020) about SAGE III/ISS ozone validation also stated that an error in ozone correction caused an underestimation of the aerosol retrievals at wavelengths near the Chappuis band at altitudes where the aerosol loading is minimal. Thomason et al. (2021) also reported a defect in these wavelengths below $20 \mathrm{~km}$ due to an error caused by the $\mathrm{O}_{4}$ cross section used in V5.1.

\subsection{OSIRIS}

OSIRIS is an instrument that measures vertical profiles of limb-scattered sunlight from the upper troposphere into the lower mesosphere. It was launched on February 2001 on board the Odin satellite and continues to take measurements to the present. The instrument measures ozone, aerosol and $\mathrm{NO}_{2}$ profiles. Initial (V5.07) aerosol retrievals were obtained by combining measurements at 470 and $750 \mathrm{~nm}$ and were reported as aerosol extinction profiles at $750 \mathrm{~nm}$. Rieger et al. (2015) compared coincident aerosol extinction observations by interpolating the SAGE II 525 and $1020 \mathrm{~nm}$ channels to the OSIRIS extinction wavelength of $750 \mathrm{~nm}$. They 
Initial validation of V1.0 CALIPSO L3 $532 \mathrm{~nm}$ stratospheric aerosol profiles is described by Kar et al. (2019). This study concluded that CALIPSO agrees well with SAGE III/ISS aerosol, with CALIPSO about $25 \%$ higher between $20-30 \mathrm{~km}$ in the tropics. However, the difference with SAGE III/ISS at the middle to high latitudes and low altitudes was substantially larger, often exceeding $100 \%$.

\section{Data comparison methodology}

In order to evaluate the accuracy of OMPS LP aerosol V2.0 retrievals, we have used a variety of methods. This includes comparison with the space-based instruments SAGE III/ISS, OSIRIS and CALIPSO, as well as performing internal consistency tests, which can quantify the uncertainty of the aerosol model assumptions and the diffuse upwelling radiance effect. To provide detailed assessment of OMPS performance at different altitudes, latitudes and times, we use two different approaches; coincident observation comparison and zonal mean climatology comparison. While the first approach is used to eliminate any geographical and time biases, the latter is proved to be useful for monitoring the health and stability of the instrument and retrieval algorithm under different conditions and periods. However, zonally averaged comparisons can produce large biases following large volcanic eruptions, where the aerosol load is high and spatially inhomogeneous, and therefore coincident comparison is preferred under these conditions (Rieger et al., 2019). The percent difference is defined as

difference $=\frac{\text { OMPS }- \text { reference }}{(\text { OMPS }+ \text { reference }) / 2} \times 100$,

where reference is the correlative measurement of aerosol extinction. All correlative aerosol profiles were interpolated to $1 \mathrm{~km}$ vertical intervals, matching OMPS LP-reported altitudes. Zonal mean climatologies were constructed using monthly mean profiles within 5 or $10^{\circ}$ latitude bins.

For all comparisons shown in this paper, the center slit aerosol retrieval is used since it has the most accurate radiometric calibration and stray light corrections (Jaross et al., 2014). The OMPS LP algorithm identifies cloud-top height using the cloud detection method described in Chen et al. (2016). However, this algorithm also flags aerosols from fresh volcanic eruptions or PyroCb events. OMPS LP V2.0 data files now contain both cloud-filtered and unfiltered data, as well as separate fields containing cloud height and type. Cloud type classifies the identified cloud as cloud, enhanced aerosol or PSC. The enhanced aerosol definition requires the cloud altitude to be at least $1.5 \mathrm{~km}$ above the tropopause. The PSC definition requires the cloud altitude to be at least $4 \mathrm{~km}$ above the tropopause and the ancillary temperature at the cloud altitude to be less than $200 \mathrm{~K}$. Users may wish to use both cloud height and cloud type flags to filter the data based on their own needs. To avoid removing aerosols from fresh volcanic or PyroCb plumes, we filtered the data by removing the extinction coefficient at and below cloud-top height only if the reported cloud-top height is in the troposphere. SAGE III is filtered for cloud contamination by using only data with an extinction ratio of 510 to $1022 \mathrm{~nm}$ greater than 2 (Thomason and Vernier, 2013), while OSIRIS and CALIPSO provide cloud-screened data.

\section{Results}

\subsection{Algorithm internal consistency}

So as to estimate the uncertainty of the assumed aerosol size distribution and phase function, we compare measurements taken at similar locations but with a different viewing geometry. Such measurements take place at high latitudes during the summer of both hemispheres, when the OMPS orbit allows observations of a given latitude in both the ascending and descending nodes. The ascending and descending nodes provide two daily observations of the same latitude, but with different scattering angles. The main assumption is that, if the retrieved aerosol values are different when the instrument is measuring the same air mass but with different scattering angle, then there is an error in the assumed phase function and ASD model. As shown by Rieger et al. (2019), the ASD errors can introduce seasonal variations that correlate well with the SSA. Herein, we compare the daily zonal mean aerosol climatology between ascending and descending nodes in the Northern Hemisphere, where the aerosol signal is stronger.

Figure 3 is a scatter plot of the difference between ascending and descending zonal mean aerosol extinction coefficient in the Northern Hemisphere between $60-90^{\circ} \mathrm{N}$, plotted as a function of the difference of the SSA of the ascending and descending nodes at three different altitudes. The figure shows that at $20.5 \mathrm{~km}$, the V2.0 algorithm has very little, if any, sensitivity to the aerosol model errors. At $16.5 \mathrm{~km}$, the dependency of the aerosol retrieval on the scattering angle shows a linear trend of $\approx 0.25 \%$ per degree for 745 and $869 \mathrm{~nm}$ and $0.5 \%$ per degree for $675 \mathrm{~nm}$. The trend is almost doubled to $-1 \%$ per degree at $25.5 \mathrm{~km}$, although it is distorted by sensor noise and inhomogeneity of the aerosol loading above the Junge layer at northern high latitudes, especially when events occur inside the polar vortex where the aerosol extinction is very low (Thomason and Poole, 1993). Nevertheless, the increase in the difference per unit of difference in SSA suggests that the aerosol model used in the retrieval is less representative of the aerosol measured at this altitude. Similar analyses made by Rieger et al. (2019) have shown that the OSIRIS V7.0 aerosol extinction SSA dependence is $0.5 \%$ per degree. 

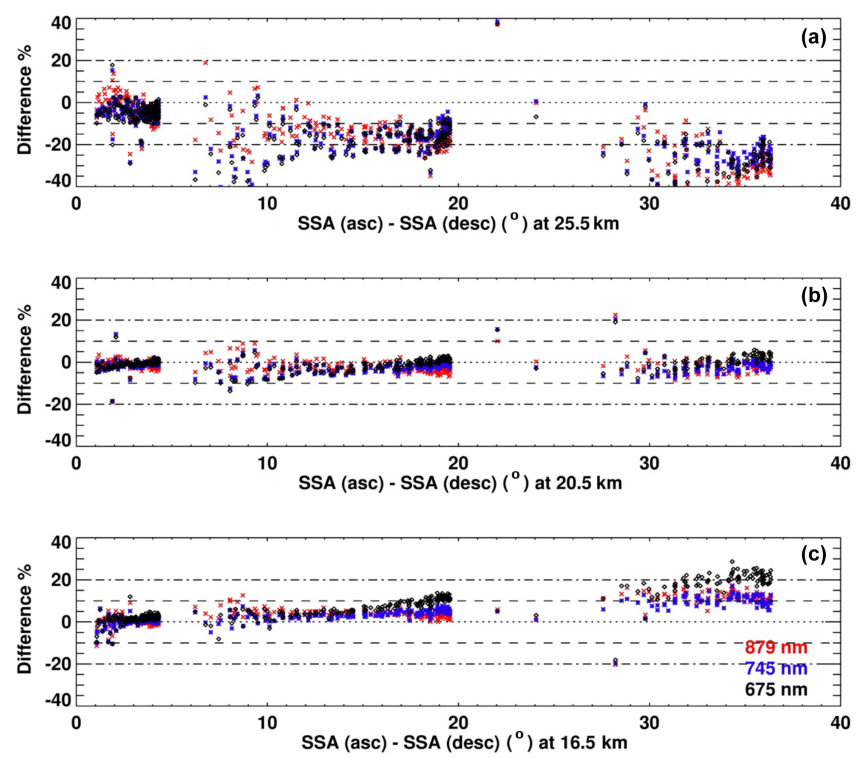

Figure 3. Scatter plot of the difference between ascending and descending aerosol extinction coefficient zonal means (\%) for 675 (black), 745 (blue) and $869 \mathrm{~nm}$ (red) vs. the difference of singlescattering angle (SSA) of the ascending and descending measurements at 25 (top), 20.5 (middle) and $16.5 \mathrm{~km}$ (bottom). Measurements where the SSA difference is less than $6^{\circ}$ are for zonal mean latitude $90-80^{\circ} \mathrm{N}, \mathrm{SSA}$ difference of $6-25^{\circ}$ is for $80-70^{\circ} \mathrm{N}$ and SSA difference of $25-36^{\circ}$ is for $70-60^{\circ} \mathrm{N}$.

\subsection{The diffuse upwelling radiance (DUR) uncertainties}

As described in Sect. 2.2.1, the aerosol retrieval algorithm uses a simple Lambertian model of the reflecting surface to estimate an effective scene reflectivity $(R)$. It does not mean the Earth's surface reflectivity, since the scene can contain clouds or aerosols. Although the sensitivity of the aerosol retrieval to diffuse upwelling radiance (DUR) uncertainties is reduced significantly by using normalized radiances (Flitther et al., 2000; Loughman et al., 2018), the error associated with assuming the Lambertian surface is difficult to estimate and possibly not negligible. In order to quantify DUR uncertainties, we compare OMPS LP daily zonal mean climatology for $R$ values less than 0.3 (cloud free) and greater than 0.3 (bright or cloudy). Figure 4 is a plot of the percent difference between the two aerosol climatologies at three different wavelengths. The three figures show a very similar picture: very large differences below the tropopause in the tropics, where the cirrus clouds are more frequent and 5\% positive bias above $20 \mathrm{~km}$, just over that cloudy region. The $5 \%$ bias may be caused by scattered light originating from cirrus clouds near the tropopause, which was not properly accounted for in the radiative transfer model (which simply used a bright Lambertian surface at sea level). Outside the tropics, the mean value of $R$ is generally greater than 0.3 , with strong seasonal dependence that peaks in the winter.
Therefore, any observed differences outside the tropics are uncorrelated with cloud presence.

\subsection{Comparison of OMPS LP with SAGE III/ISS}

\subsubsection{Coincidence comparison}

To evaluate the quality of OMPS LP aerosol retrieval with SAGE III, we use a coincidence criterion of same calendar day measurements, $\Delta$ lat $= \pm 3^{\circ}$ and $\Delta$ long $= \pm 10^{\circ}$, which is selected to minimize the effect of spatial and temporal differences between the two instruments. Coincidence pairs are averaged over 10 (Figs. 5, 7 and 8) or $40^{\circ}$ (Fig. 6) latitudes bins covering the first 2 years of SAGE III/ISS measurements.

Figure 5 depicts the mean OMPS LP and SAGE III/ISS aerosol extinction profiles for the set of coincident measurements, binned in $10^{\circ}$ latitude bins, shown at selected altitudes for four different wavelengths. In general, OMPS LP and SAGE III extinction values show similar latitudinal distribution and are well within $20 \%$ of each other for most altitudes, with $869 \mathrm{~nm}$ showing the best agreement of better than $10 \%$. At $18.5 \mathrm{~km}$ in the SH tropics, OMPS aerosol is systemically higher than SAGE III, mostly influenced by cloud presence at lower altitudes. The OMPS $675 \mathrm{~nm}$ extinction shows a negative bias at $18.5 \mathrm{~km}$ that increases with increasing latitudes in the SH, where OMPS LP observes the backscatter solar radiation, and the attenuation of Rayleigh radiation is substantial below $20 \mathrm{~km}$ at $675 \mathrm{~nm}$.

Figure 6 is a summary plot of the mean difference between OMPS and SAGE III coincidences for wavelengths 510, 600, $675,745,869$ and $997 \mathrm{~nm}$. In general, $869 \mathrm{~nm}$ is the best OMPS-retrieved wavelength relative to SAGE III with differences of $5 \%$ or less for most altitudes and latitudes. Other wavelengths agree with SAGE III to within $10 \%$. Exceptions to this occur at high altitudes (above $\approx 28 \mathrm{~km}$ ) where the aerosol loading is minimal, and near the tropopause, which is affected by cloud contamination. The 510 and $600 \mathrm{~nm}$ OMPS extinction values have a slightly larger bias of $20 \%$ in the tropics. This is due to the ozone interference in both OMPS and SAGE III $600 \mathrm{~nm}$ aerosol retrievals. The $997 \mathrm{~nm}$ OMPS extinction values have a systematic bias of $-10 \%$ between $60^{\circ} \mathrm{S}$ and $20^{\circ} \mathrm{N}$, caused by stray light contamination in the OMPS measurements. Unlike the other wavelengths, the $997 \mathrm{~nm}$ laboratory characterization is poor, and its stray light correction, therefore, has lower quality (Jaross et al., 2014). In the SH, $510 \mathrm{~nm}$ shows a large positive bias relative to SAGE III below $18 \mathrm{~km}$. This is an artifact in the OMPS retrieval algorithm, which often results in noisy and large extinction values when the measurement vector is too small relative to gaseous absorption and Rayleigh scattering (see Fig. 12).

It is worth noting that the best agreement between OMPS and SAGE is found in the NH, where OMPS observes in forward scattering and the weighting function is strong for all wavelengths. In that region, the agreement is mostly within 
(a) Aergt 0.3 - Aerit 0.3 (745 nm)

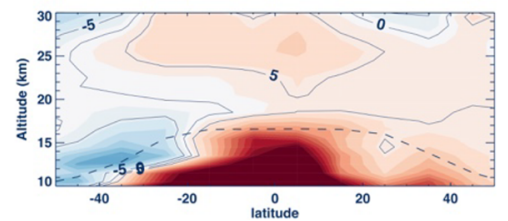

(b) Aergt $0.3-$ Aerit $0.3(869 \mathrm{~nm})$

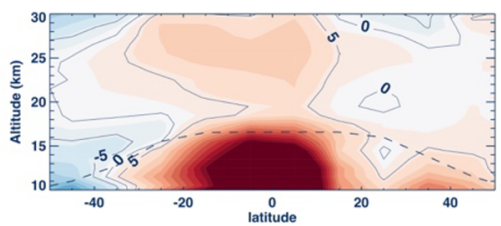

(c) Aer ${ }^{0.3}-\operatorname{Aer}$ it $0.3(997 \mathrm{~nm})$

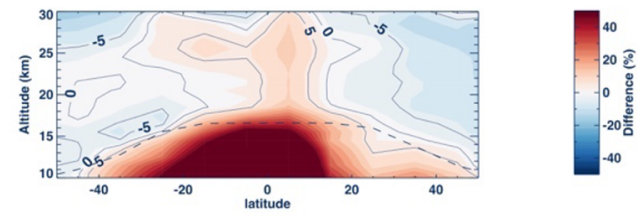

Figure 4. Panels (a) through (c) show the difference between the aerosol climatology when reflectivity is greater than 0.3 and when reflectivity is less than 0.3. Extinction climatology at 745,869 and $997 \mathrm{~nm}$. The dashed line is tropopause altitude. The contour line shows differences greater than $\pm 5 \%$.
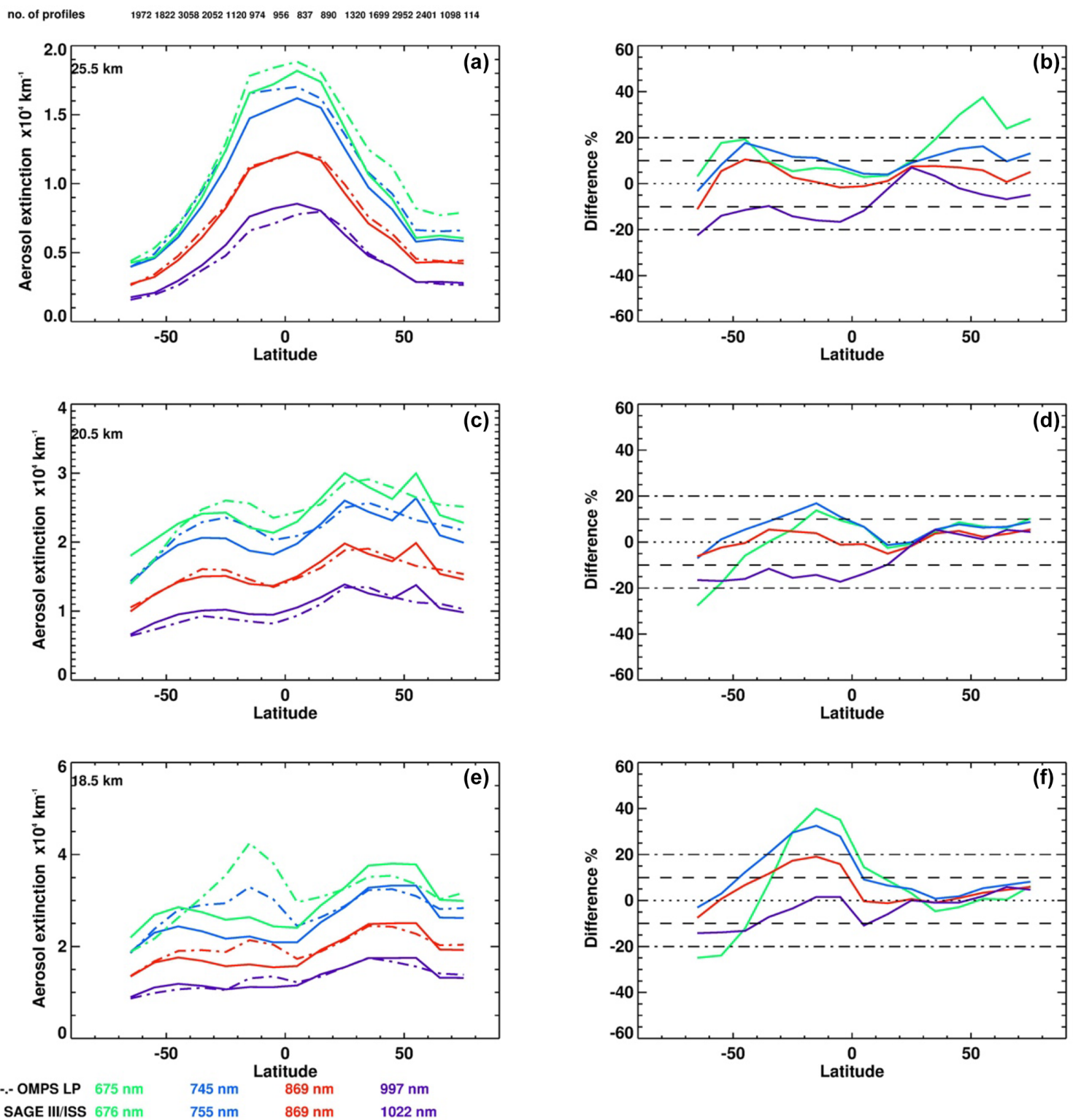

Figure 5. Panels (a), (c) and (e) are OMPS v2.0 (dash) and SAGE III (solid) aerosol extinction coefficient $\left(\times 10^{4} \mathrm{~km}^{-1}\right)$ at $25.5,20.5$ and $18.5 \mathrm{~km}$, for 675 (green), 745 (blue), 869 (red) and $997 \mathrm{~nm}$ (violet). Panels (b), (d) and (f) are the percent difference between the two measurements. The number of coincidences for each zone is shown in the left top panel. 

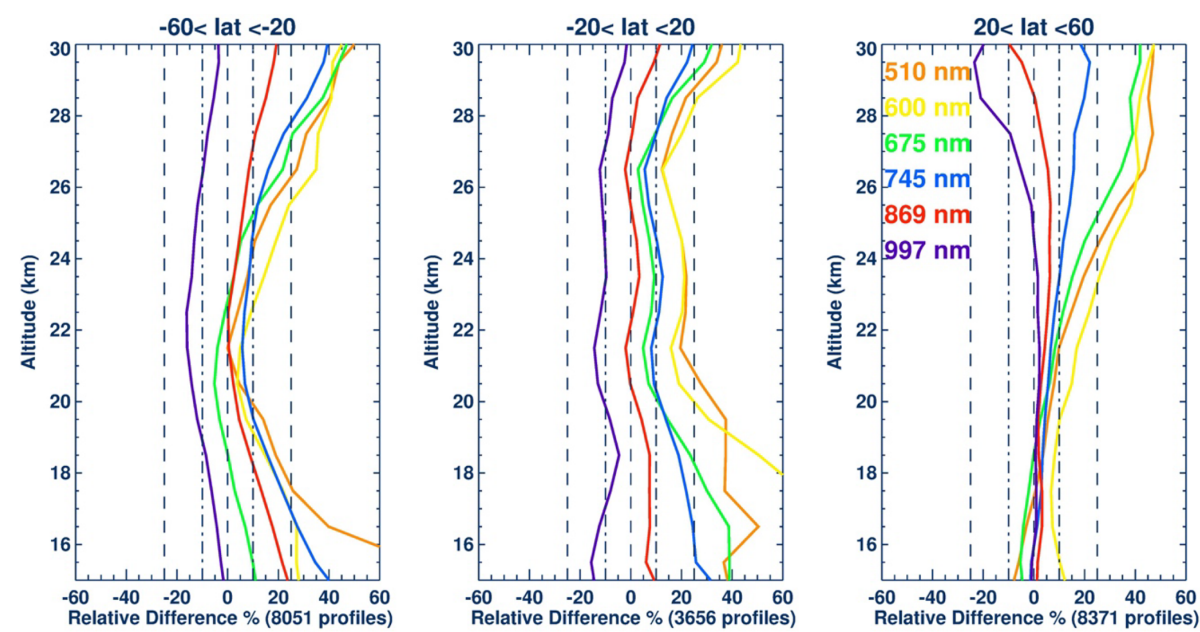

Figure 6. Summary plot of the average percent difference between OMPS LP and SAGE III profiles in percent at three different latitudinal zones for six wavelengths: 510 (orange), 600 (yellow), 675 (green), 745 (blue), 869 (red) and $997 \mathrm{~nm}$ (violet).

$5 \%$ for an altitude between 14 and $22 \mathrm{~km}$. Above $24 \mathrm{~km}$, the observed biases for 510, 600, 675 and, to some extent, 745,869 and $997 \mathrm{~nm}$ gradually increase with altitude, mainly caused by instrument noise and errors under low-aerosol conditions, although OMPS assumed aerosol size model uncertainty also contributes to the larger differences.

Figure 7 summarizes the quality of OMPS LP aerosol extinction at six retrieved wavelengths, showing the zonally averaged mean differences between OMPS LP and SAGE III aerosol (in percent). Below $25 \mathrm{~km}$, the differences between OMPS LP and SAGE III are largely driven by OMPS weighting functions or Jacobians. The weaker Jacobians for short wavelengths under backscatter conditions in the SH and below $20 \mathrm{~km}$ lead to limited accuracy, while stronger Jacobians at the longer wavelengths improve its accuracy significantly (Taha et al., 2011; Rieger et al., 2019). Overall, the shorter wavelengths $(510,600$ and $675 \mathrm{~nm})$ are biased low against SAGE III with a difference greater than $25 \%$ below $20 \mathrm{~km}$ in the SH. In addition, these short wavelengths exhibit pronounced large aerosol in the tropics below $20 \mathrm{~km}$ caused by the algorithm's reduced accuracy when the measurement vector is very small. The agreement is well within $25 \%$ at the altitude range $20-25 \mathrm{~km}$ and better in the $\mathrm{NH}$. Above $25 \mathrm{~km}$, the comparison between the two instruments is poor, caused by either SAGE III ozone correction errors and/or OMPS reduced sensitivity to aerosol at these short wavelengths. The best agreement between OMPS and SAGE III can be seen at 869 and $997 \mathrm{~nm}$, where they are mostly within $10 \%$ of each other for all altitudes and latitudes. The $745 \mathrm{~nm}$ OMPS extinction agrees with SAGE to within $15 \%$ everywhere except for the SH tropics below $18 \mathrm{~km}$.

The standard deviation shown in Fig. 8 is influenced by several factors: OMPS LP uncertainties such as measurement noise, forward model errors and retrieval algorithm sensitivities, in addition to SAGE III/ISS's own uncertainty and atmo- spheric variability. In general, the standard deviation is $15 \%-$ $20 \%$ for altitudes that show good agreement with SAGE III (Fig. 7). The large standard deviation of $\approx 50 \%$ at high altitude is due to instrument noise and low aerosol loading. Below $20 \mathrm{~km}$, the standard deviations for the shorter wavelengths increase to $50 \%$, caused by the OMPS LP reduced accuracy. In the UT-LS, the standard deviation is $>50 \%$ due to larger dynamical variability, especially during periods when dispersal of plumes due to volcanic eruptions and other events causes longitudinal variations, as well as cloud interference.

Based on the comparison with SAGE III, we can estimate the OMPS aerosol retrieval relative accuracy to be $\approx 10 \%$ for 745,869 and $997 \mathrm{~nm}$ in the stratosphere and $20 \%$ for $675 \mathrm{~nm}$ above $20 \mathrm{~km}$ and in the NH. The 510 and $600 \mathrm{~nm}$ retrievals have limited accuracy in the $\mathrm{SH}$ and $25 \%$ relative accuracy at altitudes between $20-26 \mathrm{~km}$ and in the NH. Furthermore, the standard deviation can be used to determine the retrieval relative precision, which can be estimated to be better than $15 \%$ for the longer wavelengths and close to $20 \%$ for wavelengths less than $745 \mathrm{~nm}$. The real precision is probably better than the quoted values since the calculated standard deviation includes atmospheric variability and both instruments' biases, none of which was removed (Rault and Taha, 2007; Wang et al., 2020).

\subsubsection{Zonal mean comparison}

In order to investigate the OMPS LP retrieval performance under different seasonal or geographical conditions, we compare the OMPS LP monthly zonal mean time series with the SAGE III/ISS monthly zonal mean time series for four wavelengths at three different altitudes. The comparison is also divided into three different regions, the SH (Fig. 9), tropics (Fig. 10) and NH (Fig. 11). In general, the agreement be- 

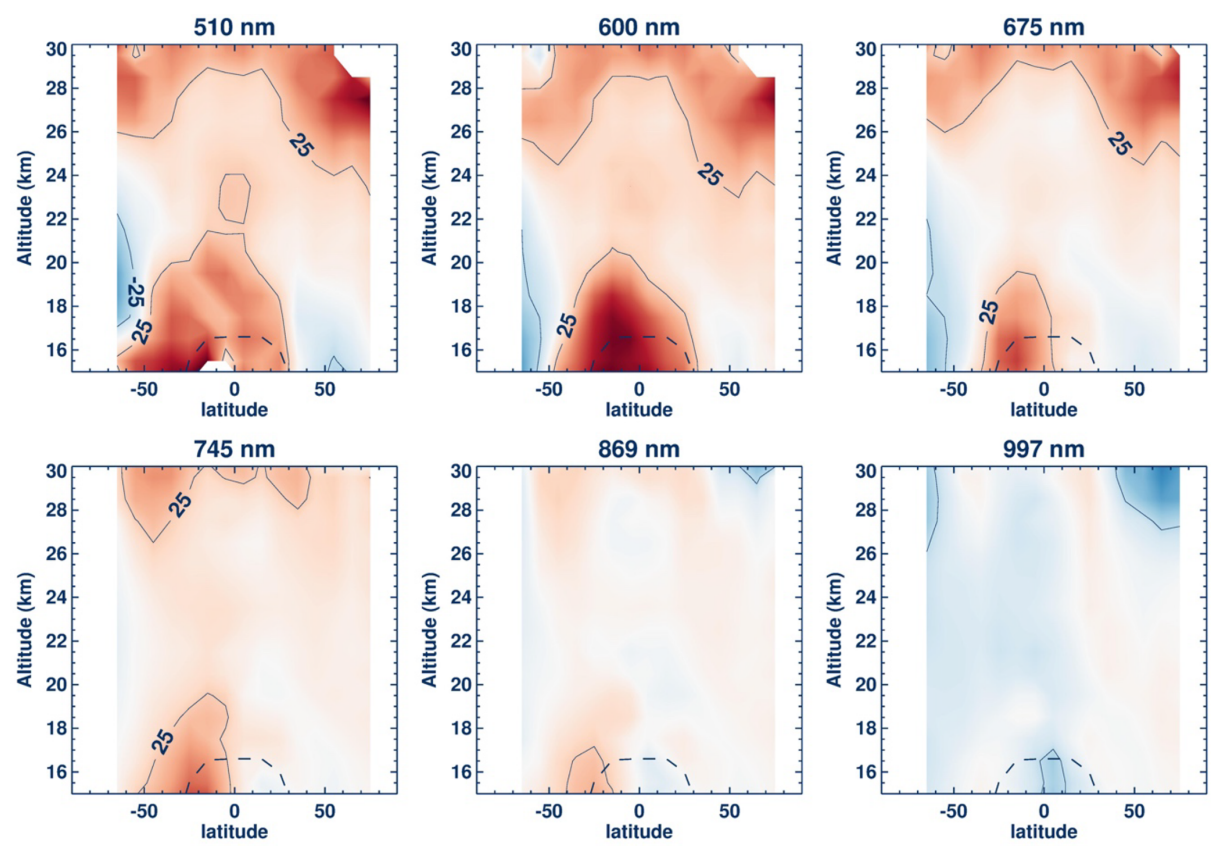

Difference (\%)

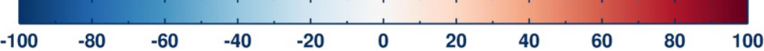

Figure 7. Mean differences between OMPS LP and SAGE III extinctions as a function of latitude and altitude at 510, 66, 675, 745, 869 and $997 \mathrm{~nm}$, zonally averaged at $10^{\circ}$ latitudes. The contour line shows differences greater than $\pm 25 \%$, and dashed line is the tropopause altitude. Positive differences (in percent) indicate the OMPS LP values are higher than SAGE III/ISS.
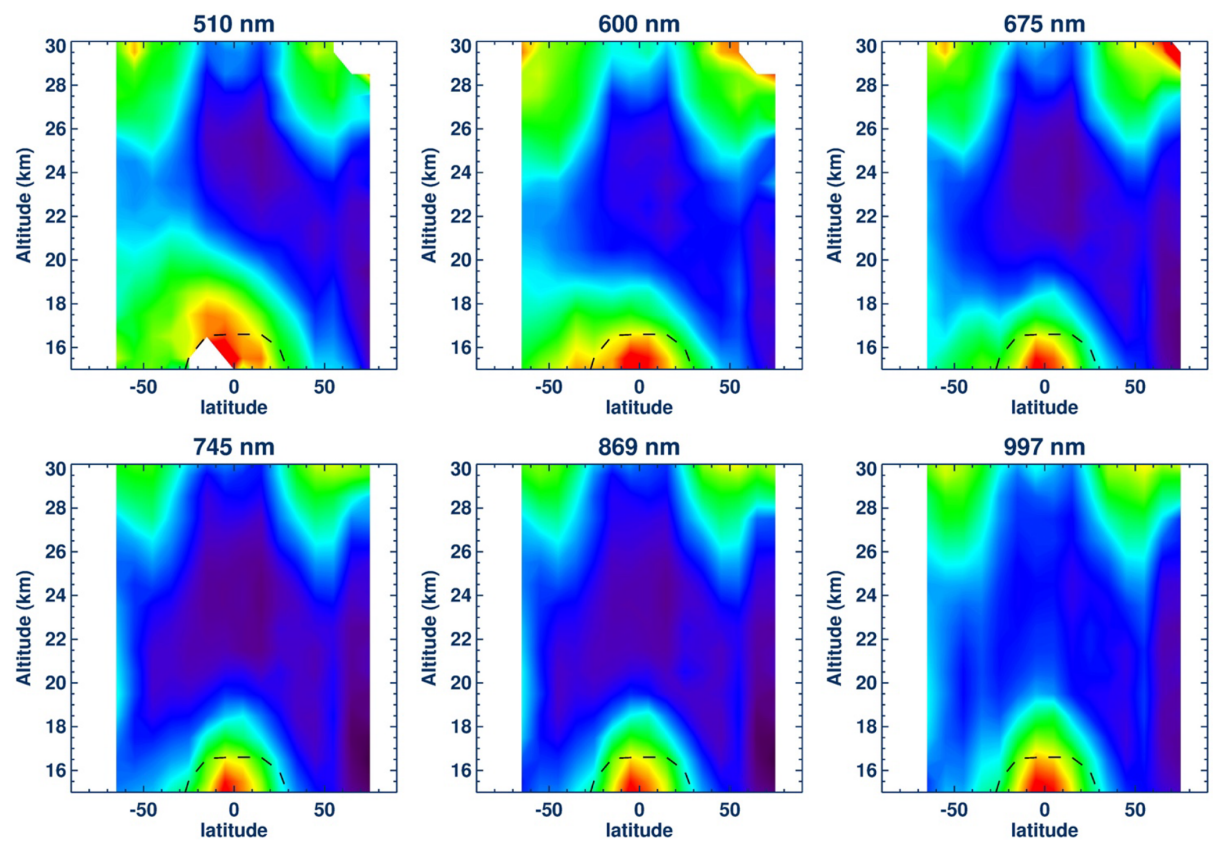

The standard deviation of the difference (\%)

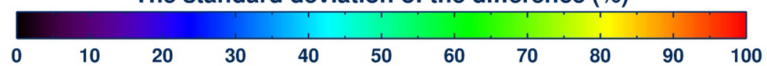

Figure 8. Same as Fig. 7 but for the $1-\sigma$ standard deviation or spread of difference between OMPS LP and SAGE III. 

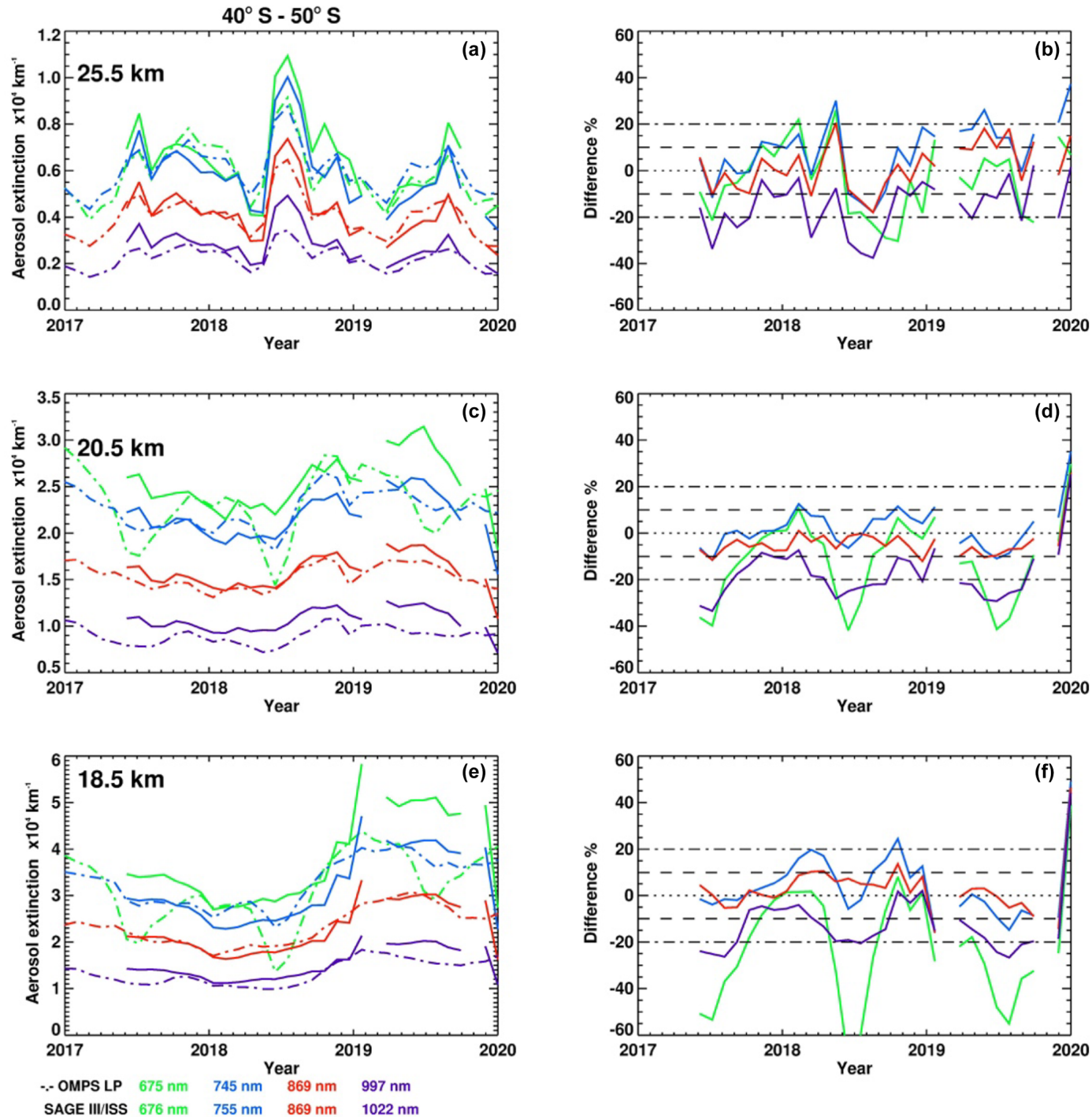

Figure 9. Panels (a), (c) and (e) are OMPS LP (dashed) and SAGE III/ISS (solid) aerosol extinction monthly zonal mean at 675, 745, 869 and $997 \mathrm{~nm}$, latitude zone $40-50^{\circ} \mathrm{S}$ for altitudes 25.5 (top), 20.5 (middle) and $18.5 \mathrm{~km}$ (bottom), from 2017 to 2019 . Panels (b), (d) and (f) are the percent difference.

tween the two instruments in the SH is mostly within $10 \%-$ $20 \%$. The $675 \mathrm{~nm}$ extinction at $20.5 \mathrm{~km}$ is a notable exception, as the OMPS LP aerosol extinction values drop significantly when the SSA is greater than $145^{\circ}$, and the attenuation of Rayleigh scattering below $20 \mathrm{~km}$ becomes significant. This behavior appears as an apparent seasonal pattern, in which the OMPS LP/SAGE III difference becomes much larger during $\mathrm{SH}$ winter months. It is therefore recommended that OMPS aerosol measurements at $\lambda \leq 675 \mathrm{~nm}$ should be excluded when SSA is greater than $145^{\circ}$ below $21 \mathrm{~km}$.

A similar agreement is found in the tropics, at or above $20.5 \mathrm{~km}$, with the exception of the first few months following the Aoba volcanic eruption in July 2018, where OMPS LP initially reported higher aerosol extinction than SAGE III. This might be caused by the different coverage and fre- quency of measurements for each instrument. Still, the difference between the two measurements was mostly within $20 \%$ in the aftermath of this volcanic eruption. At $18.5 \mathrm{~km}$, the difference is often greater than $20 \%$, reaching more than $60 \%$ following the subsidence of the volcanic plume. The reason for such large differences is unclear as OMPS LP still shows elevated aerosol levels when SAGE III measurements indicate that the aerosol values are back to pre-eruption levels, although spatial variability and spatial resolutions can contribute to such large differences. SAGE III aerosol extinction profiles are produced on a $0.5 \mathrm{~km}$ grid with an estimated vertical resolution of $0.7 \mathrm{~km}$ (SAGE III ATBD, 2002; Thomason et al., 2010) while OMPS LP vertical sampling is $1.0 \mathrm{~km}$ with an instantaneous resolution of $1.5 \mathrm{~km}$ (Jaross et al., 2014). Bourassa et al. (2019) compared nearby OMPS 

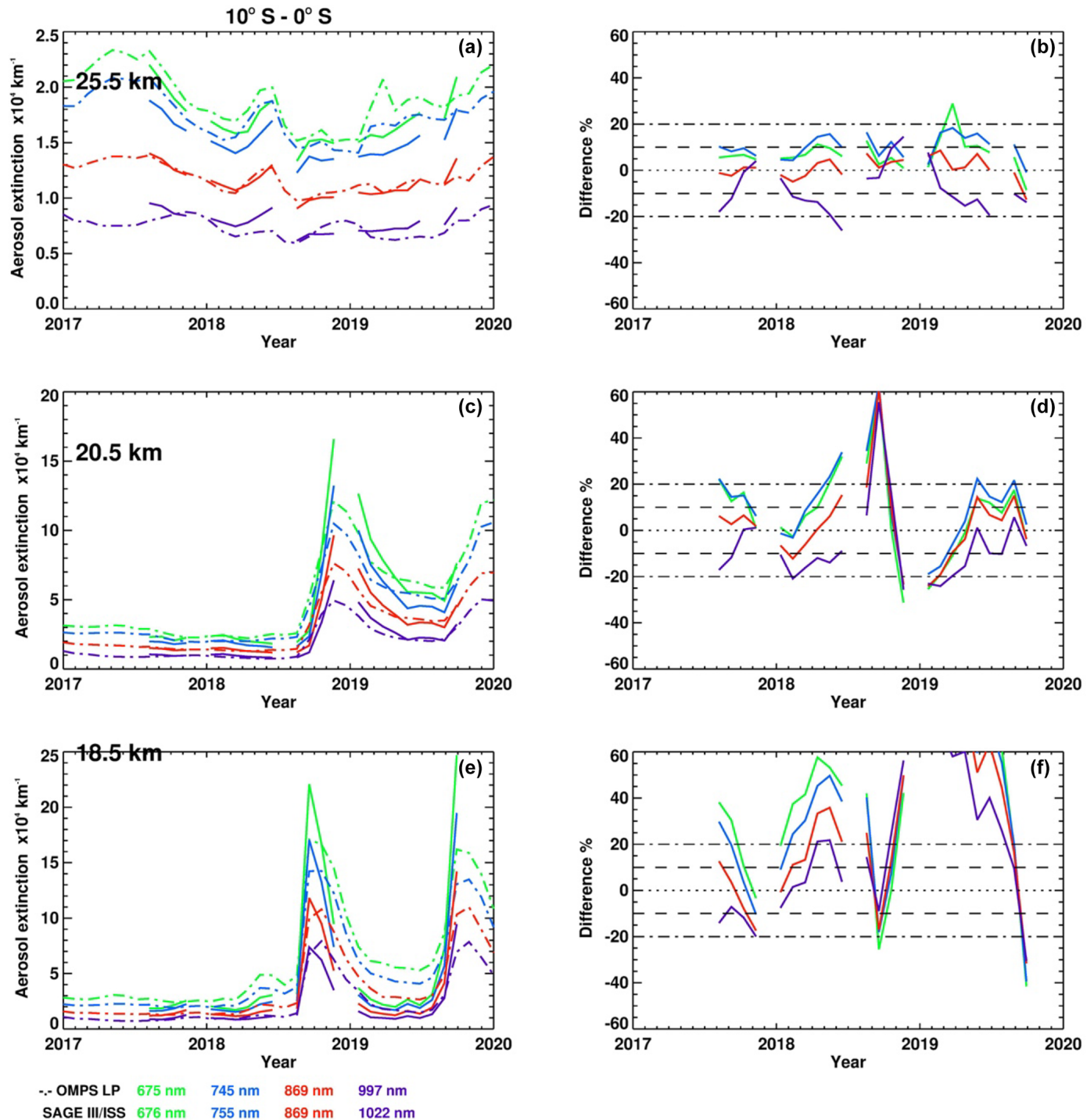

Figure 10. Same as Fig. 9 but for latitude zone $10-0^{\circ} \mathrm{S}$.

LP and SAGE III/ISS aerosol profiles following the aftermath of the British Columbia fires in 2017. They showed that both instruments have very similar layered vertical structure and magnitude. However, they noted that some differences in layer height and magnitude can be expected from differing vertical resolutions. Another possible explanation is that OMPS LP cloud clearing can be incomplete, and residual cloud contamination can contribute to the large differences near the tropopause. The best agreement between the two instruments can be found at $25.5 \mathrm{~km}$, well within $10 \%$.

In the NH, all OMPS LP wavelengths show similar robust agreement to SAGE III, mostly within $10 \%$, since OMPS LP observes in the forward scattering and all wavelengths are strongly sensitive to aerosol (Fig. 11). A notable exception is the first couple of months of the August 2017 Canadian PyroCb period and the June 2019 Raikoke eruption, when the aerosol loading was very high and spatially inhomogeneous. Spatial inhomogeneity also caused a large bias after 2018 following the sharp drop in aerosol extinction at $25.5 \mathrm{~km}$. While the OMPS assumed ASD model may contribute to the larger differences at $25.5 \mathrm{~km}$, instrument noise and calibration errors are also more significant under low-aerosol conditions. OMPS LP $997 \mathrm{~nm}$ is affected by stray light contamination at the normalization altitudes in the NH high latitudes, which might explain the negative bias during 2019. On the other hand, SAGE III ozone correction uncertainty near the Chappuis band can cause a dip in SAGE III aerosol extinction measurements at $676 \mathrm{~nm}$. In particular, the SAGE III $676 \mathrm{~nm}$ values at $25.5 \mathrm{~km}$ are either zero or negative during 2019 when the measured aerosol is at its lowest levels in the $\mathrm{NH}$ during the short lifetime of ISS SAGE III. 

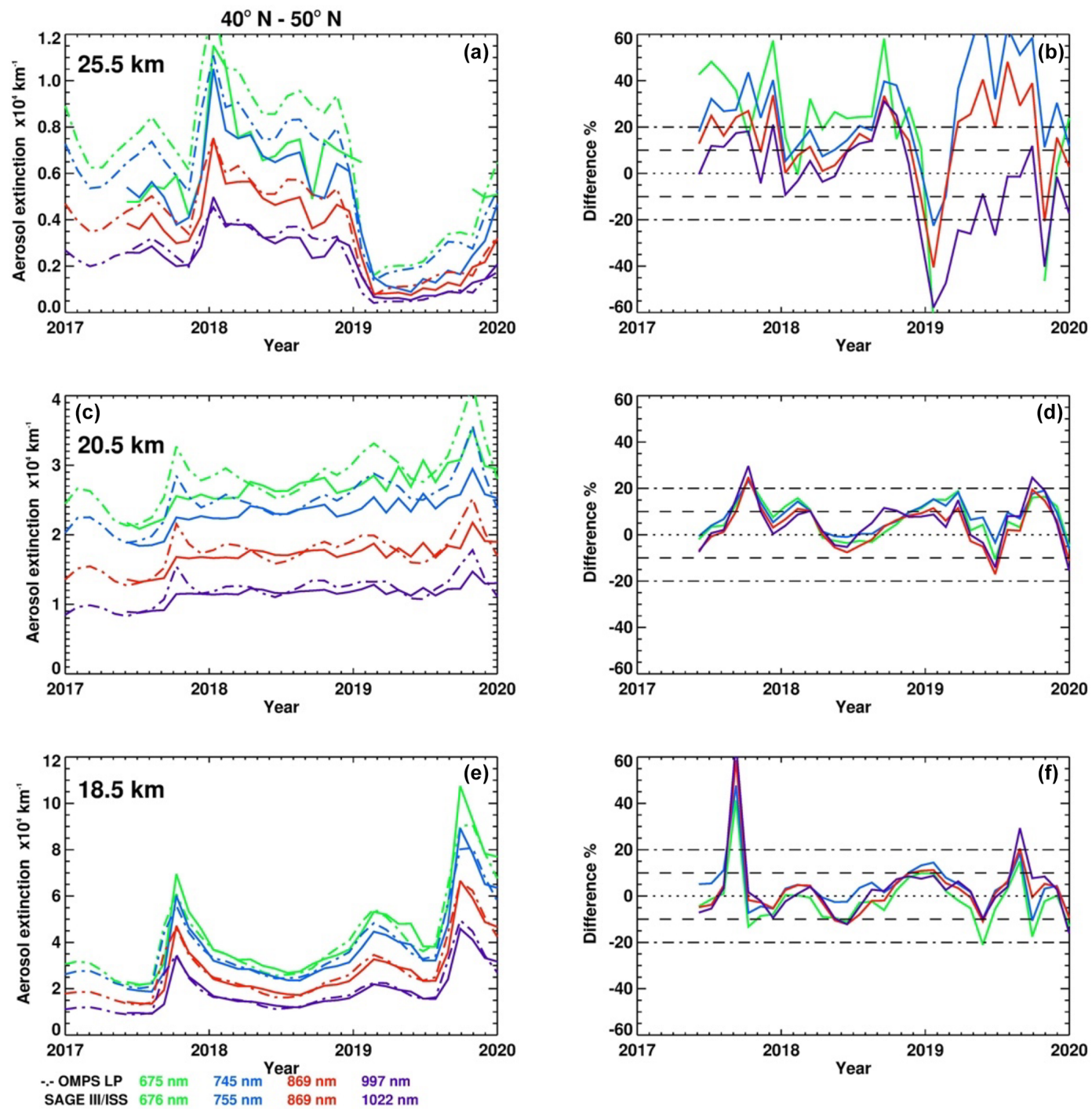

Figure 11. Same as Fig. 9 but for latitude zone $40-50^{\circ} \mathrm{N}$.

\subsection{Comparison of OMPS LP with OSIRIS and CALIPSO}

In this section, we compare OMPS LP aerosol at 510 and $745 \mathrm{~nm}$ with V7 OSIRIS at $750 \mathrm{~nm}$ and V1 L3 CALIPSO at both 532 and $745 \mathrm{~nm}$. CALIPSO $532 \mathrm{~nm}$ extinction (allaerosol mode) is converted to $745 \mathrm{~nm}$ using an Ångström exponent of 1.9, similar to the Angström exponent for the OMPS assumed aerosol model. We also included SAGE III/ISS measurements at $755 \mathrm{~nm}$ as an independent reference, since SAGE measurements are widely considered to be the most accurate stratospheric aerosol dataset (SPARC, 2006; von Savigny et al., 2015; Kremser et al., 2016; Thomason et al., 2018; Kar et al., 2019). Although coverage and sampling differences can make such comparisons difficult, it provides a chance to evaluate the entire OMPS LP data record relative to these two datasets. As both OSIRIS and CALIPSO

approach the ends of their lives, it is now more critical than ever to extend the stratospheric aerosol record that has been developed from SAGE-OSIRIS-CALIPSO into OMPS LPSAGE III/ISS records.

Figures 12, 13 and 14 show OMPS LP, SAGE III/ISS, OSIRIS and CALIPSO zonally averaged monthly mean aerosol extinction coefficient at three different altitudes in the $\mathrm{SH}$, tropics and $\mathrm{NH}$, respectively, spanning a period between 2012 and 2019. The right panel is the mean difference in percent between OMPS LP and all instruments for the same altitudes and latitudes. In general, OMPS LP, OSIRIS, CALIPSO and SAGE III aerosol measurements are closely matched at all altitudes, showing enhanced aerosol following the eruptions of Nabro (June 2011), Kelut (February 2014), Calbuco (April 2015), Aoba (July 2018), Raikoke (June 2019) and Ulawun (August 2019), as well as the Canadian fires (August 2017). At $25.5 \mathrm{~km}$ in the tropics, OMPS 

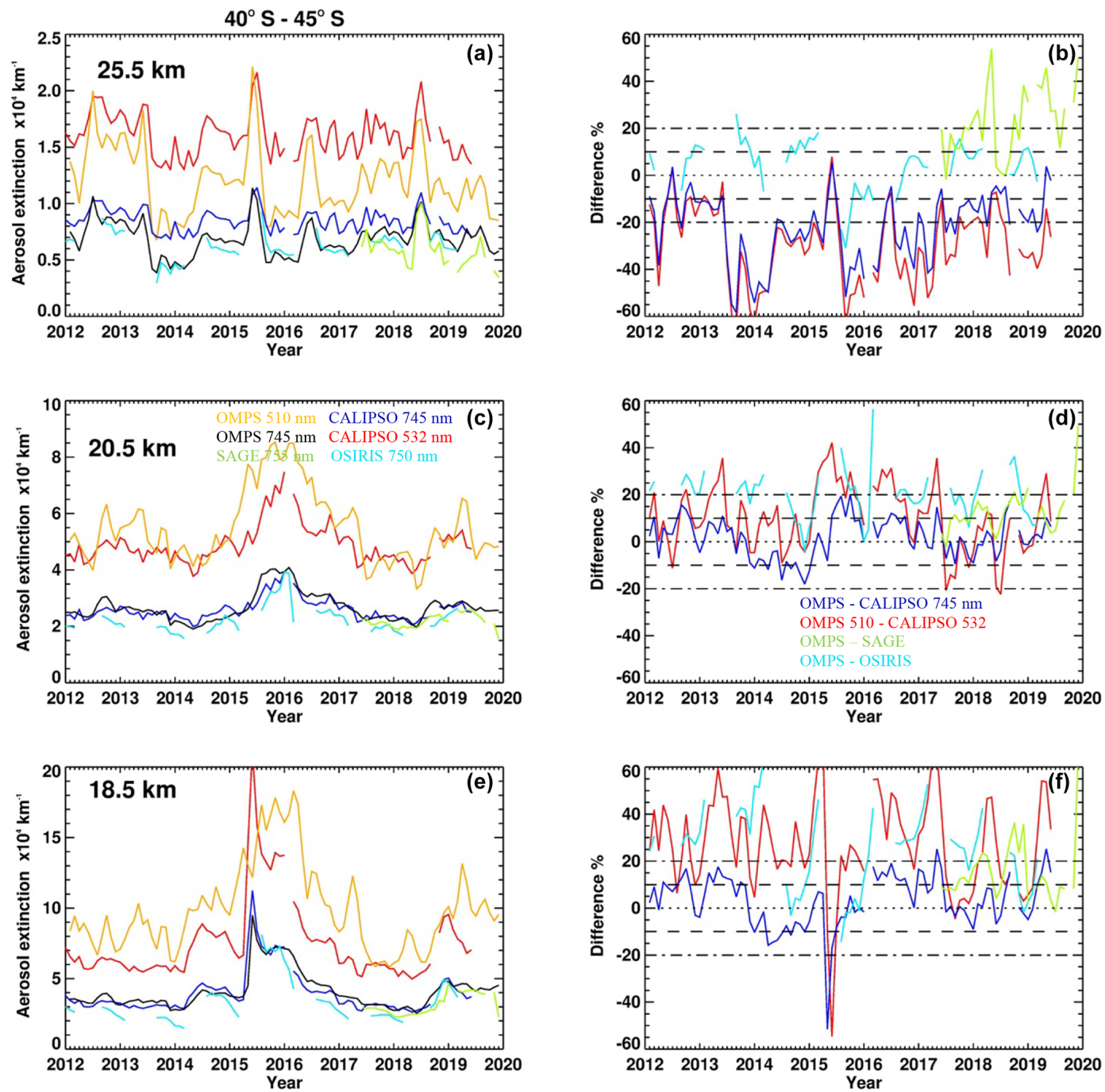

Figure 12. Panels (a), (c) and (e) are CALIPSO 532 (red) and 745 (blue), OMPS LP 510 (orange) and 745 (black), OSIRIS 750 (light blue), and SAGE III/ISS $755 \mathrm{~nm}$ (green) aerosol extinction monthly zonal mean, latitude zone 40-45 $\mathrm{S}$ for altitudes 25.5 (top), 20.5 (middle) and $18.5 \mathrm{~km}$ (bottom), from 2012 to 2019. Panels (b), (d) and (e) are the percent difference between OMPS LP and other instruments.

LP, CALIPSO and OSIRIS clearly show an enhanced aerosol layer within 1 year of each volcanic eruption, lofted into this altitude by the upwelling tropical branch of the BrewerDobson circulation (Vernier et al., 2011b). Notice that agreement between OMPS LP and the three instruments is generally within $20 \%$ for all shown altitudes, except for $25.5 \mathrm{~km}$ in the $\mathrm{SH}$, where CALIPSO is somewhat biased high, and in the tropics at or below $20.5 \mathrm{~km}$, where the aerosol loading is greatly enhanced by several moderate volcanic eruptions. Part of this large difference can be due to aerosol model uncertainties, as both OMPS LP and OSIRIS assume a fixed background aerosol model, while CALIPSO uses a fixed lidar ratio. In addition, differences at $18.5 \mathrm{~km}$ in the tropics can be affected by residual cloud contamination, as all three instruments use different criteria for screening cloudy events. Kar et al. (2019) reported that CALIPSO has larger biases
2-3 km above the tropopause that might be due to cloud contamination. The OMPS LP $510 \mathrm{~nm}$ comparison shows good agreement with CALIPSO at $20.5 \mathrm{~km}$ in the $\mathrm{SH}$, with periods of larger difference when the SSA is greater than $120^{\circ}$ in the SH. At $18.5 \mathrm{~km}$, the difference is also $20 \%$, with OMPS exhibiting periodic jumps in the aerosol extinction values at $510 \mathrm{~nm}$, caused by the algorithm's reduced accuracy when the magnitude of the measurement vector is very small (see Fig. 1). At $25.5 \mathrm{~km}$, both the 510 and $745 \mathrm{~nm}$ extinction values show similar variability to CALIPSO, well within $25 \%$, except for the $\mathrm{SH}$. In the $\mathrm{NH}$, the accuracy of the $510 \mathrm{~nm}$ aerosol retrieval is comparable to the $745 \mathrm{~nm}$ accuracy. OSIRIS monthly means in the $\mathrm{NH}$ are slightly noisier because of the limited number of profiles used.

A summary of the comparison between OMPS LP and CALIPSO is shown in Fig. 15a and b. The differences be- 
(a)

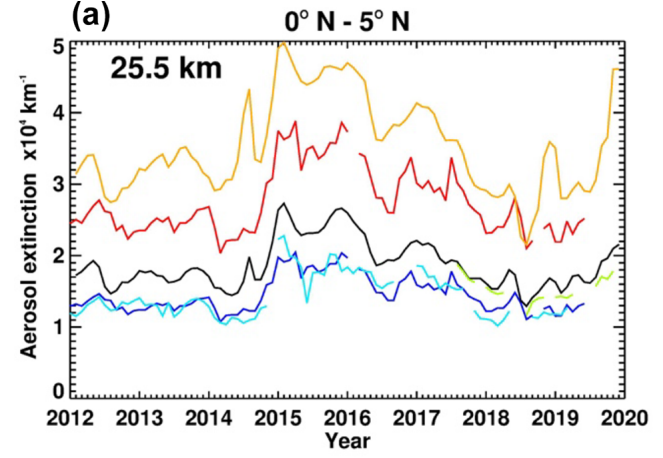

(c)

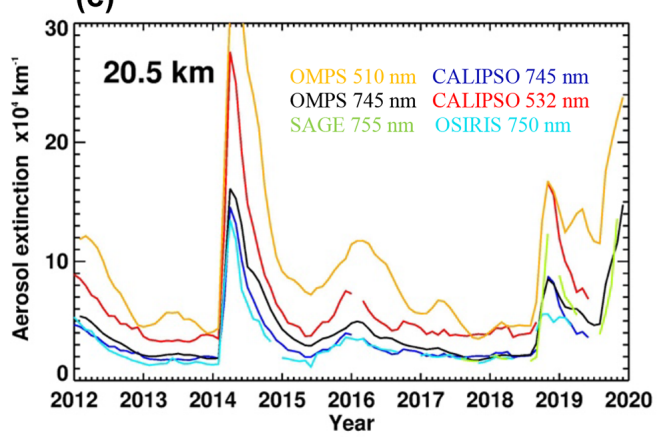

(e)

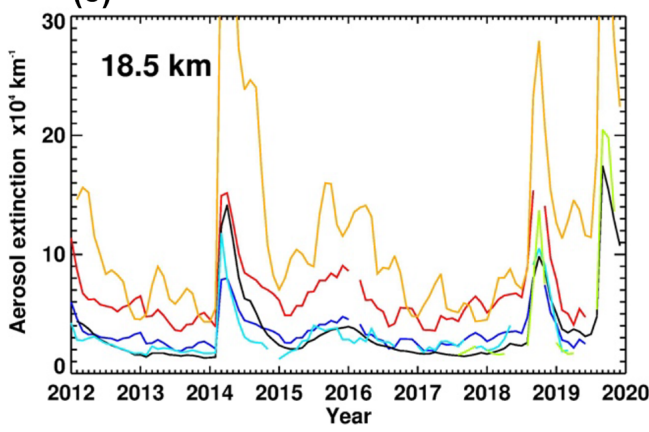

(b)

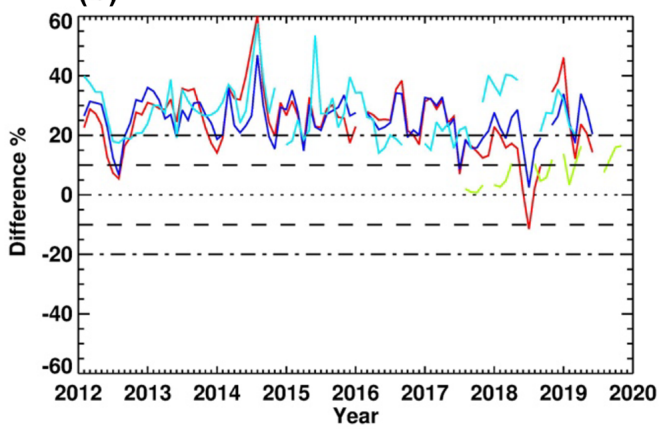

(d)
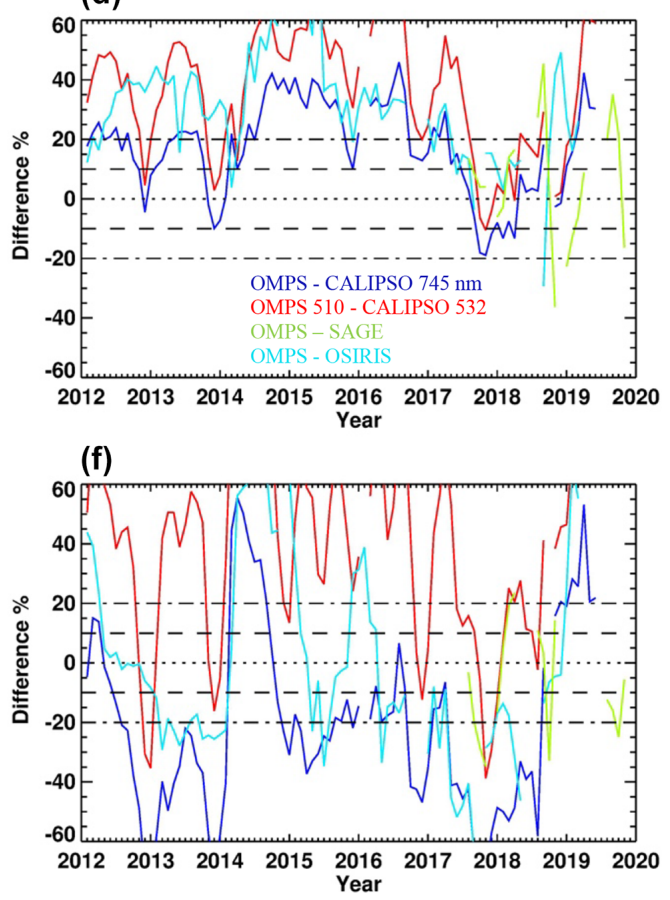

Figure 13. Panels (a), (c) and (e) are CALIPSO 532 (red) and 745 (blue), OMPS LP 510 (orange) and 745 (black), OSIRIS 750 (light blue), and SAGE III/ISS $755 \mathrm{~nm}$ (green) aerosol extinction monthly zonal mean, latitude zone 0 and $5^{\circ} \mathrm{N}$ for altitudes 25.5 (top), 20.5 (middle) and $18.5 \mathrm{~km}$ (bottom), from 2012 to 2019. Panels (b), (d) and (e) are the percent difference between OMPS LP and other instruments.

tween OMPS LP and CALIPSO are, in general, within $25 \%$ between $50^{\circ} \mathrm{S}$ and $50^{\circ} \mathrm{N}$, except for the tropics, which are closer to $25 \%$ at some altitudes and greater in the case of $510 \mathrm{~nm}$. The difference is substantially large in middle to high latitudes of both hemispheres, with CALIPSO showing a rather large bias of $50 \%$ and exceeding $100 \%$ at altitudes above $25 \mathrm{~km}$. This is also consistent with an earlier study that shows the agreement of $25 \%$ between CALIPSO and SAGE III/ISS between $30^{\circ} \mathrm{S}$ and $30^{\circ} \mathrm{N}$ and larger biases of $100 \%-200 \%$ at the middle to high latitudes (Kar et al., 2019). They also noted that the primary parameter affecting the comparison is likely the fixed lidar ratio of $50 \mathrm{sr}$ used in the CALIPSO retrieval, which is dependent on the aerosol optical and physical properties. It is plausible that the comparison between OMPS and CALIPSO can be further improved by using a different lidar ratio.
Agreement between OMPS LP and OSIRIS (Fig. 15c) is generally very good, with differences less than $20 \%$ for most latitudes in the stratosphere below $30 \mathrm{~km}$, except for the tropics, where OSIRIS is $30 \%$ lower compared to OMPS. The reason for the increased differences in the tropics is unclear; however, a similar negative bias of $15 \%$ was also noted for comparisons in the tropics between OSIRIS and SAGE III/ISS (Rieger et al., 2019), while OMPS $745 \mathrm{~nm}$ has $10 \%$ positive bias in the tropics relative to SAGE III/ISS (Fig. 5). Combining both biases might explain the difference seen in the tropics. The large bias seen at NH high latitudes above $25 \mathrm{~km}$ is consistent with the comparison with SAGE III and CALIPSO and highlights the difficulties of retrieving very low aerosol for both instruments. Rieger et al. (2018) also reported a large negative bias at high latitude above $25 \mathrm{~km}$ 

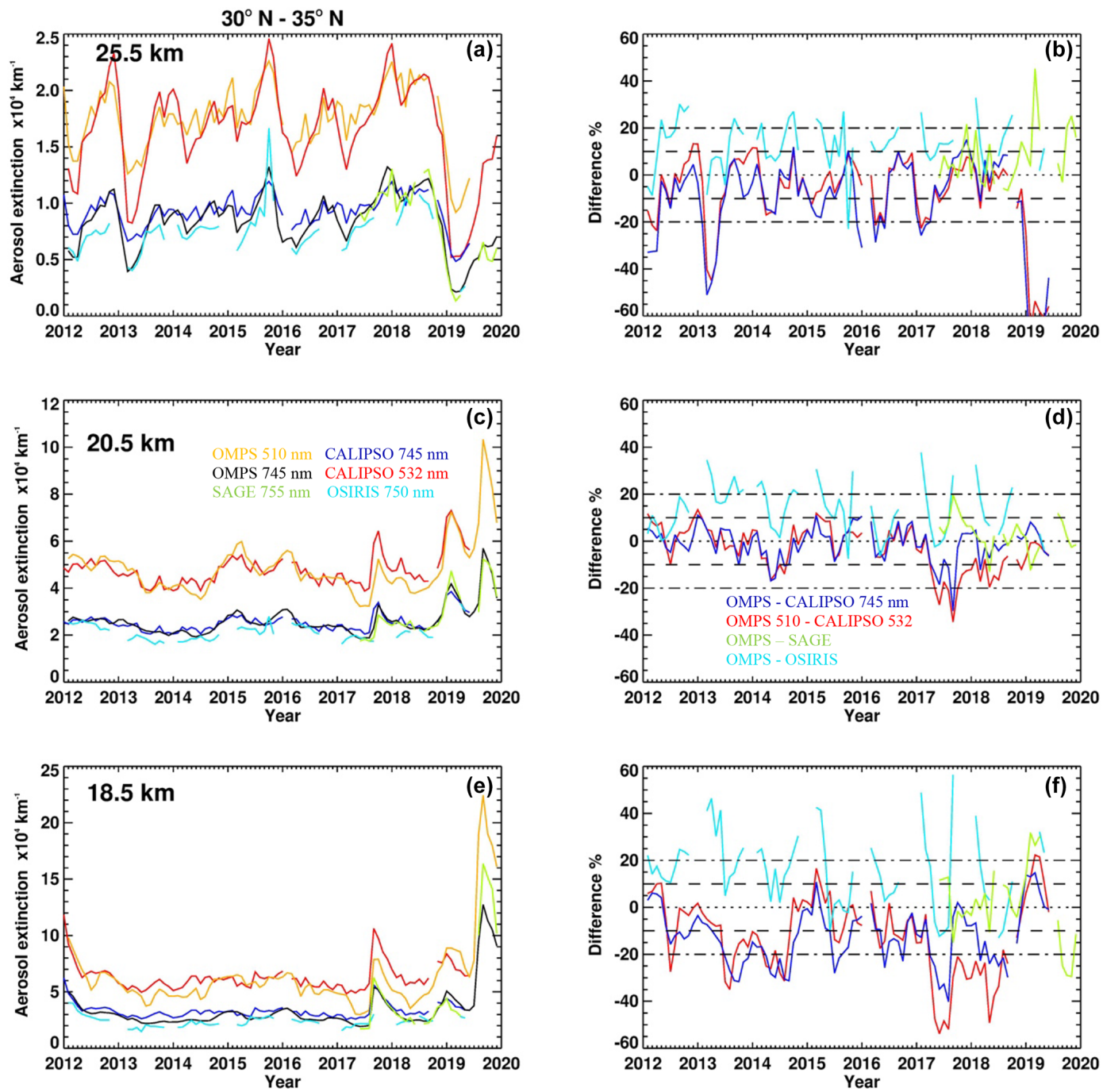

Figure 14. Panels (a), (c) and (e) are CALIPSO 532 (red) and 745 (blue), OMPS LP 510 (orange) and 745 (black), OSIRIS 750 (light blue), and SAGE III/ISS $755 \mathrm{~nm}$ (green) aerosol extinction monthly zonal mean, latitude zone 30 and $35^{\circ} \mathrm{N}$ for altitudes 25.5 (top), 20.5 (middle) and $18.5 \mathrm{~km}$ (bottom), from 2012 to 2019. Panels (b), (d) and (e) are the percent difference between OMPS LP and other instruments.

when comparing OSIRIS to SAGE II that is caused by nonzero aerosol in the normalization altitudes.

Similar to the previous comparison with SAGE III (Fig. 7), the standard deviation for the three comparisons is generally less than $15 \%$ for altitudes that show good agreement with either CALIPSO or OSIRIS (Fig. 15d, e and f). There is a large standard deviation of $\approx 50 \%$ above $22 \mathrm{~km}$ at the SH high latitudes due to OMPS reduced accuracy under low aerosol loading and large scattering angle. In the UT-LS, the standard deviation is greater than $40 \%$ due to larger dynamical variability, especially during volcanic eruptions and cloud interference.

\subsection{Recommendations for use of OMPS LP aerosol extinction data}

OMPS LP provides good quality multi-wavelength aerosol extinction retrievals that can be useful for scientific studies. In particular, we find the relative accuracy at 745,869 and $997 \mathrm{~nm}$ is on the order of $10 \%$ and relative precision better than $15 \%$ in the primary aerosol layer in the stratosphere. These retrievals are suitable for continuing the long-term record of stratospheric aerosol that was started by SAGE II in 1984, although the OMPS $997 \mathrm{~nm}$ retrieval is affected by stray light contamination and shows slight negative bias in the SH. Since the 869 and $997 \mathrm{~nm}$ retrievals have the strongest sensitivity to aerosol in almost all altitudes and regions, these are most suitable for scientific studies like detection and tracking periodic events when aerosol particles are 


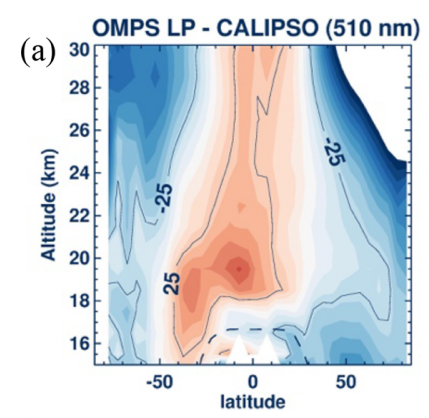

(d)

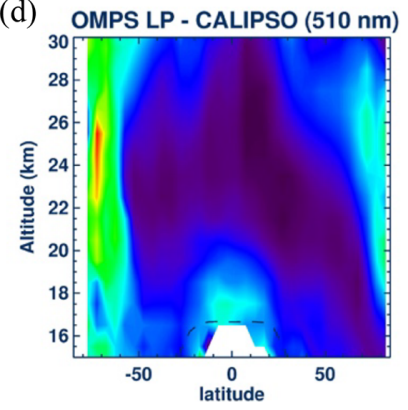

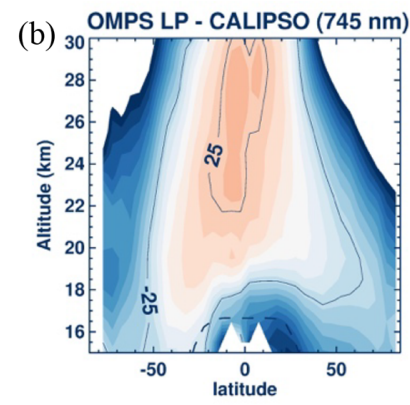

(e) OMPS LP - CALIPSO (745 nm)

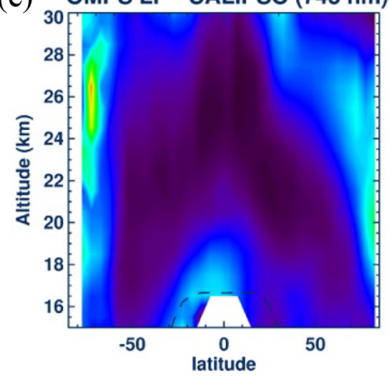

(c)

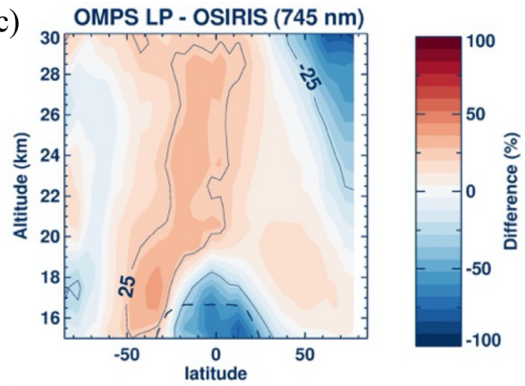

(f)

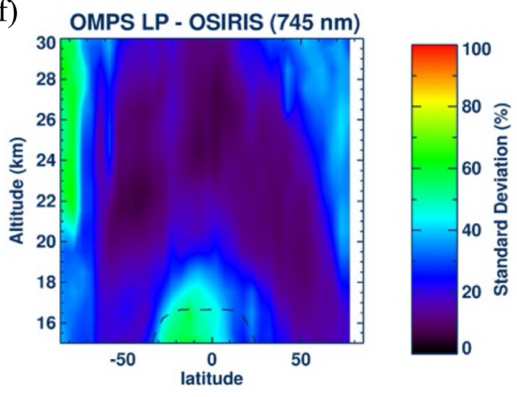

Figure 15. Panels (a)-(c) show the mean difference between OMPS LP and (a) CALIPSO 532, (b) CALIPSO 745, and (c) OSIRIS 745 nm measurements in percent. The dashed line is the tropopause altitude, and the contour line is for differences greater than $\pm 25 \%$. Panels (d)(f) are the same as the top panels but for the $1-\sigma$ standard deviation or spread of difference between OMPS LP and CALIPSO 510 (d), CALIPSO 745 (e), and OSIRIS $745 \mathrm{~nm}$ (f).

injected into the stratosphere, such as volcanic eruptions or PyroCb events. The $675 \mathrm{~nm}$ relative accuracy is on the order of $20 \%$ above $20 \mathrm{~km}$, and its relative precision is $15 \%$. In the $\mathrm{SH}$, its accuracy is reduced, with measurements deemed unusable when the SSA exceeds $145^{\circ}$. We find $600 \mathrm{~nm}$ of comparable accuracy to $675 \mathrm{~nm}$ at altitudes of 20-25 km, which suggests that the applied ozone corrections at this wavelength are reasonable. Still, we recommend the user avoid using this channel since it is only meant for diagnostic purposes. The $510 \mathrm{~nm}$ relative accuracy is $25 \%$ at a limited altitude range of $20-24 \mathrm{~km}$ in the SH and tropics, with similar accuracy in the $\mathrm{NH}$ for all altitudes below $25 \mathrm{~km}$. Because of its weak sensitivity to aerosol in the backscatter, we recommend cautious use of the $510 \mathrm{~nm}$ retrieval, only in the $\mathrm{NH}$. We also recommend that the user be cautious when attempting to derive aerosol size information from quantities such as Ångström exponent, since the accuracy of each wavelength retrieval is affected by its weighting function at some altitudes and latitudes, and the $997 \mathrm{~nm}$ retrieval is affected by stray light contamination, which may bias the result.

\section{Conclusions}

The new V2.0 OMPS LP aerosol extinction products at wavelengths 510, 600, 675, 745, 869 and $997 \mathrm{~nm}$ have been processed. Comparisons with coincident measurements by the SAGE III/ISS, OSIRIS and CALIPSO instruments indicate that the OMPS LP retrievals are suitable for scien- tific studies. By comparing OMPS measurements at different scattering angles, we demonstrate that the retrieval's dependency on viewing geometry is negligible at $20.5 \mathrm{~km}$ and decreased significantly for the longer wavelengths at lower altitudes relative to the short wavelengths. In addition, we estimate the uncertainty in the aerosol retrieval caused by diffuse upwelling radiance (DUR) to be on the order of $5 \%$. The 745, 869 and $997 \mathrm{~nm}$ extinction profiles in the stratosphere are shown to be the most accurate and most suitable for continuing the long-term record of stratospheric aerosol, with relative accuracies and precisions close to $10 \%$ and $15 \%$, respectively, while the relative accuracy and precision of $675 \mathrm{~nm}$ extinction profiles are on the order of $20 \%$. Differences can be larger for individual profiles or zonal mean comparison, which can be affected by differences in instrument's coverage and inhomogeneity along the line of sight for fresh volcanic eruptions. The $510 \mathrm{~nm}$ extinction profile was shown to have limited accuracy in the SH and is only recommended for use between $20-24 \mathrm{~km}$ and in the NH. The $600 \mathrm{~nm}$ extinction profile is mainly retrieved for diagnostic purposes and is not recommended for scientific use. Future versions of the OMPS LP retrieval algorithm may improve on the assumed aerosol size model to account for the different types of aerosol at different altitudes. Additionally, a better cloud clearing that can utilize OMPS wavelength dependence may further improve the aerosol products in the UT-LS region. 
Code and data availability. OMPS-NPP LP L2 Aerosol Extinction Vertical Profile swath multi-wavelength daily 3slit Collection 2 V2.0 data are accessible from the Goddard Earth Sciences Data and Information Services Center (GES DISC), https://doi.org/10.5067/CX2B9NW6FI27 (Taha, 2020). SAGE III/ISS data (https://doi.org/10.5067/ISS/SAGEIII/ SOLAR_HDF4_L2-V5.1, NASA/LARC/SD/ASDC, 2017) and CALIPSO data (https://doi.org/10.5067/CALIOP/CALIPSO/ LID_L3_STRATOSPHERIC_APRO-STANDARD-V1-00, NASA/LARC/SD/ASDC, 2018) are accessible at the NASA Atmospheric Sciences Data Center. The OSIRIS dataset can be downloaded from https://research-groups.usask.ca/osiris/ data-products.php\#Download (Roth, 2020). Data analysis products shown here are available from the corresponding author.

Author contributions. GT and RL were responsible for the development of the OMPS LP V2.0 multi-wavelength algorithm, which is described in this paper. TZ was responsible for code improvements and testing. GT wrote the initial draft of the paper with help from RL. GT carried out the analysis shown here. LT participated in the scientific discussion about SAGE III data. JK participated in the scientific discussion about CALIPSO data. LR and AB participated in the scientific discussion in regard to OSIRIS. All authors reviewed the manuscript and provided advice on the text and figures.

Competing interests. The authors declare that they have no conflict of interest.

Special issue statement. This article is part of the special issue "New developments in atmospheric Limb measurements: Instruments, Methods and science applications (AMT/ACP inter-journal SI)". It is a result of the 10th international limb workshop, Greifswald, Germany, 4-7 June 2019.

Acknowledgements. The authors would like to thank the OMPS LP characterization team led by Glen Jaross for producing the Level1 gridded data; the OMPS ozone SIPS team led by Matt Deland and Colin Seftor for Level-2 data production; and the OSIRIS, CALIPSO and SAGE III-ISS teams for providing the data used in this study.

Financial support. This research has been supported by the National Aeronautics and Space Administration, Goddard Space Flight Center (grant no. 80NSSC18K0847).

Review statement. This paper was edited by Christian von Savigny and reviewed by Chris Sioris and one anonymous referee.

\section{References}

Bourassa, A. E., Degenstein, D. A., Gattinger, R. L., and Llewellyn, E. J.: Stratospheric aerosol retrieval with optical spectrograph and infrared imaging system limb scatter measurements, J. Geophys. Res.-Atmos., 112, D10217, https://doi.org/10.1029/2006JD008079, 2007.

Bourassa, A., Rieger, L., Zawada, D. J., Khaykin, S., Thomason, L., and Degenstein, D.: Satellite limb observations of unprecedented forest fire aerosol in the stratosphere, J. Geophys. Res., 124, 9510-9519, https://doi.org/10.1029/2019JD030607, 2019.

Brock, C. A., Schröder, F., Kärcher, B., Petzold, A., Busen, R., and Fiebig, M.: Ultrafine particle size distributions measured in aircraft exhaust plumes, J. Geophys. Res., 105, 26555-26567, https://doi.org/10.1029/2000JD900360, 2000.

Chahine, M.: Inverse problems in radiative transfer: A determination of atmospheric parameters, J. Atmos. Sci., 27, 960-967, https://doi.org/10.1175/15200469(1970)027<0960:IPIRTD>2.0.CO;2, 1970.

Chen, Z., DeLand, M., and Bhartia, P. K.: A new algorithm for detecting cloud height using OMPS/LP measurements, Atmos. Meas. Tech., 9, 1239-1246, https://doi.org/10.5194/amt-9-12392016, 2016.

Chen, Z., Bhartia, P. K., Loughman, R., Colarco, P., and DeLand, M.: Improvement of stratospheric aerosol extinction retrieval from OMPS/LP using a new aerosol model, Atmos. Meas. Tech., 11, 6495-6509, https://doi.org/10.5194/amt-116495-2018, 2018.

Chepfer, H., Bony, S., Winker, D., Cesana, G., Dufresne, J., Minnis, P., Stubenrauch, C., and Zeng, S.: The GCM-oriented CALIPSO cloud product (CALIPSO-GOCCP), J. Geophys. Res.-Atmos., 115, D00H16, https://doi.org/10.1029/2009jd012251, 2010.

Chouza, F., Leblanc, T., Barnes, J., Brewer, M., Wang, P., and Koon, D.: Long-term (1999-2019) variability of stratospheric aerosol over Mauna Loa, Hawaii, as seen by two co-located lidars and satellite measurements, Atmos. Chem. Phys., 20, 6821-6839, https://doi.org/10.5194/acp-20-6821-2020, 2020.

Chu, W. P., McCormick, M. P., Lenoble, J., Brogniez, C., and Pruvost, P.: SAGE II inversion algorithm, J. Geophys. Res., 94, 8339-8351, https://doi.org/10.1029/JD094iD06p08339, 1989.

Cisewski, M., Zawodny, J., Gasbarre, J., Eckman, R., Topiwala, N., Rodriguez-Alverez, O., Cheek, D., and Hall, S.: The Stratospheric Aerosol and Gas Experiment (SAGE III) on the International Space Station (ISS) Mission, Proc. SPIE 9241, Sensors, Systems, and Next-Generation Satellites XVIII, 924107 (11 November 2014), Amsterdam, the Netherlands, https://doi.org/10.1117/12.2073131, 2014.

Deshler, T.: A review of global stratospheric aerosol: Measurements, importance, life cycle, and local stratospheric aerosol, Atmos. Res., 90, 223-232, https://doi.org/10.1016/j.atmosres.2008.03.016, 2008.

Fairlie, T. D., Vernier, J.-P., Natarajan, M., and Bedka, K. M.: Dispersion of the Nabro volcanic plume and its relation to the Asian summer monsoon, Atmos. Chem. Phys., 14, 7045-7057, https://doi.org/10.5194/acp-14-7045-2014, 2014.

Flittner, D. E., Bhartia, P. K., and Herman, B. M.: $\mathrm{O}_{3}$ profiles retrieved from limb scatter measurements: Theory, Geophys. Res. Lett., 27, 2601-2604, 2000.

Fromm, M., Lindsey, D. T., Servranckx, R., Yue, G., Trickl, T., Sica, R., Doucet, P., and Godin-Beekmann, S.: The untold story of 
pyrocumulonimbus, Bull. Am. Meteorol. Soc., 91, 1193-1209, https://doi.org/10.1175/2010BAMS3004.1, 2010.

Gorkavyi, N., Rault, D. F., Newman, P. A., da Silva, A. M., and Dudorov, A. E.: New stratospheric dust belt due to the Chelyabinsk bolide, Geophys. Res. Lett., 40, 4734-4739, https://doi.org/10.1002/grl.50788, 2013.

Hofmann, D. J. and Deshler, T.: Stratospheric cloud observations during formation of the Antarctic ozone hole in 1989, J. Geophys. Res., 96, 2897-2912, 1991.

Hofmann, D. J. and Solomon, S.: Ozone destruction through heterogeneous chemistry following the eruption of El Chichón, J. Geophys. Res., 94, 5029-5041, 1989.

Hayashida, S., Saitoh N., Kagawa A., Yokota T., Suzuki M., Nakajima H., and Sasano Y.: Arctic polar stratospheric clouds observed with the Improved Limb Atmospheric Spectrometer during winter 1996/1997, J. Geophys. Res., 105, 24715-24730, 2000.

Hervig, M. E., Russell, J., Gordley, L. L., Park, J. H., Drayson, S. R., and Deshler, T.: Validation of aerosol measurements from the Halogen Occultation Experiment, J. Geophys. Res., 101, 1026710275, https://doi.org/10.1029/95JD02464, 1996.

Jaeger, H. and Deshler, T.: Lidar backscatter to extinction, mass and area conversions for stratospheric aerosols based on midlatitude balloonborne size distribution measurements, Geophys. Res. Lett., 29, 1929, https://doi.org/10.1029/2002GL015609, 2002.

Jaeger, H., Long-term record of lidar observations of the stratospheric aerosol layer at Garmisch-Partenkirchen, J. Geophys. Res., 110, D08106, https://doi.org/10.1029/2004JD005506, 2005.

Jaross, G., Bhartia, P. K., Chen, G., Kowitt, M., Haken, M., Chen, Z., Xu, P., Warner, J., and Kelly, T.: OMPS Limb Profiler instrument performance assessment, J. Geophys. Res., 119, 43994412, https://doi.org/10.1002/2013JD020482, 2014.

Jonsson, H. H., Wilson, J. C., Brock C. A., Knollenberg, R. G., Newton, R., Dye, J. E., Baumgardner, D., Borrmann, S., Ferry, G. V., Pueschel, R., Woods, D. C., and Pitts, M. C.: Performance of a focused cavity aerosol spectrometer for measurements in the stratosphere of particle size in the $0.06-2.0 \mu \mathrm{m}$ Diameter Range, J. Ocean. Atmos. Technol., 12, 115-129, https://doi.org/10.1175/15200426(1995)012<0115:POAFCA >2.0.CO;2, 1995.

Junge, C. E., Chagnon, C. W., and Manson, J. E.: A world-wide stratospheric aerosol layer, Science, 133, 1478-1479, 1961.

Kar, J., Lee, K.-P., Vaughan, M. A., Tackett, J. L., Trepte, C. R., Winker, D. M., Lucker, P. L., and Getzewich, B. J.: CALIPSO level 3 stratospheric aerosol profile product: version 1.00 algorithm description and initial assessment, Atmos. Meas. Tech., 12, 6173-6191, https://doi.org/10.5194/amt-12-6173-2019, 2019.

Kovilakam, M., Thomason, L. W., Ernest, N., Rieger, L., Bourassa, A., and Millán, L.: The Global Space-based Stratospheric Aerosol Climatology (version 2.0): 1979-2018, Earth Syst. Sci. Data, 12, 2607-2634, https://doi.org/10.5194/essd-12-26072020, 2020.

Kremser, S., Thomason, L. W., Hobe, M., Hermann, M., Deshler, T., Timmreck, C., Toohey, M., Stenke, A., Schwarz, J. P.,Weigel, R., Fueglistaler, S., Prata, F. J., Vernier, J.-P., Schlager, H., Barnes, J. E., Antu na-Marrero, J.-C., Fairlie, D., Palm, M., Mahieu, E., Notholt, J., Rex, M., Bingen, C., Vanhellemont, F., Bourassa, A.,Plane, J. M. C., Klocke, D., Carn, S. A., Clarisse, L., Trickl,
T., Neely, R., James, A. D., Rieger, L., Wilson, J. C., and Meland, B.: Stratospheric aerosol-Observations, processes, and impact on climate, Rev. Geophys., 54, 278-335, 2016.

Llewellyn, E., Lloyd, N. D., Degenstein, D. A., Gattinger, R. L., Petelina, S. V., Bourassa, A. E., Wiensz, J. T., Ivanov, E. V., McDade, I. C., Solheim, B. H., McConnell, J. C., Haley, C. S., von Savigny, C., Sioris, C. E., McLinden, C. A., Griffioen, E., Kaminski, J., Evans, W. F. J., Puckrin, E., Strong, K., Wehrle, V., Hum, R. H., Kendall, D. J. W., Matsushita, J., Murtagh, D.P., Brohede, S., Stegman, J., Witt, G., Barnes, G., Payne, W. F., Piché, L., Smith, K., Warshaw, G., Deslauniers, D. L., Marchand, P., Richardson, E. H., King, R. A., Wevers, I., McCreath, W., Kyrölä, E., Oikarinen, L., Leppelmeier, G. W., Auvinen, H., Megie, G., Hauchecorne, A., Lefevre, F., de La Nöe, J., Ricaud, P., Frisk, U., Sjoberg, F., von Schéele, F., and Nordh, L.: The OSIRIS instrument on the Odin spacecraft, Can. J. Phys., 82, 411-422, https://doi.org/10.1139/P04-005, 2004.

Loughman, R. P., Griffioen, E., Oikarinen, L., Postylyakov, O. V., Rozanov, A., Flittner, D. E., and Rault, D. F.: Comparison of radiative transfer models for limb-viewing scattered sunlight measurements, J. Geophys. Res., 109, D06303, https://doi.org/10.1029/2003JD003854, 2004.

Loughman, R., Flittner, D., Nyaku, E., and Bhartia, P. K.: GaussSeidel limb scattering (GSLS) radiative transfer model development in support of the Ozone Mapping and Profiler Suite (OMPS) limb profiler mission, Atmos. Chem. Phys., 15, 30073020, https://doi.org/10.5194/acp-15-3007-2015, 2015.

Loughman, R., Bhartia, P. K., Chen, Z., Xu, P., Nyaku, E., and Taha, G.: The Ozone Mapping and Profiler Suite (OMPS) Limb Profiler (LP) Version 1 aerosol extinction retrieval algorithm: theoretical basis, Atmos. Meas. Tech., 11, 2633-2651, https://doi.org/10.5194/amt-11-2633-2018, 2018.

Lumpe, J. D., Bevilacqua, R. M., Hoppel, K. W., and Randall, C.E.: POAM III retrieval algorithm and error analysis, J. Geophys. Res., 107, 4575, https://doi.org/10.1029/2002JD002137, 2002.

Malinina, E., Rozanov, A., Rozanov, V., Liebing, P., Bovensmann, H., and Burrows, J. P.: Aerosol particle size distribution in the stratosphere retrieved from SCIAMACHY limb measurements, Atmos. Meas. Tech., 11, 2085-2100, https://doi.org/10.5194/amt-11-2085-2018, 2018.

McCormick, M. P., Steele H. M., Hamill P., Chu W. P., Swissler T. J.: Polar stratospheric cloud sightings by SAM II, J. Atmos. Sci., 39, 1387-1397, 1982

McElroy, C. T., Nowlan, C. R., Drummond, J. R., Bernath, P. F., Barton, D. V., Dufour, D. G., Midwinter, C., Hall, R. B., Ogyu, A., Ullberg, A., Wardle, D. I., Kar, J., Zou, J., Nichitiu, F., Boone, C. D., Walker, K. A., and Rowlands, N.: The ACE-MAESTRO instrument on SCISAT: Description, performance, and preliminary results, Appl. Opt., 46, 4341-4356, 2007.

McLinden, C. A., Olsen, S., Hannegan, B., Wild, O., Prather, M. J., and Sundet, J.: Stratospheric ozone in 3-D models: A simple chemistry and the cross-tropopause flux, J. Geophys. Res., 105, 14653-14665, 2000.

McPeters, R. D. and Labow, G. J.: Climatology 2011: An MLS and sonde derived ozone climatology for satellite retrieval algorithms, J. Geophys. Res., 117, D10303, https://doi.org/10.1029/2011JD017006, 2012. 
Medhaug, I. Stolpe, M. B., Fischer, E. M. and Knutti, Reconciling controversies about the "global warming hiatus", Nature 545, 41-47, https://doi.org/10.1038/nature22315, 2017.

NASA/LARC/SD/ASDC: SAGE III/ISS L2 Solar Event Species Profiles (HDF-EOS) V051, https://doi.org/10.5067/ISS/ SAGEIII/SOLAR_HDF4_L2-V5.1, 2017.

NASA/LARC/SD/ASDC: CALIPSO Lidar Level 3 Stratospheric Aerosol Profiles Standard V1-00, available at: $\quad$ https://doi.org/10.5067/CALIOP/CALIPSO/LID_L3_ STRATOSPHERIC_APRO-STANDARD-V1-00, 2018.

Peterson, D. A., Campbell, J. R., Hyer, E. J., Fromm, M. D., Kablick, G. P., Cossuth, J. H., and DeLand, M. T.: Wildfire-driven thunderstorms cause a volcano-like stratospheric injection of smoke, NPJ Clim. Atmos. Sci., https://doi.org/10.1038/s41612-018-0039-3, 2018.

Poole, L. R. and McCormick, M. P.: Airborne lidar observations of Arctic polar stratospheric cloud: Indications of two distinct growth stages, Geophys. Res. Lett., 15, 21-23, 1988.

Rasch, P. J., Crutzen P. J., and Coleman D. B.: Exploring the geoengineering of climate using stratospheric sulfate aerosols: The role of particle size, Geophys. Res. Lett., 35, L02809, https://doi.org/10.1029/2007GL032179, 2008.

Rault, D. F. and Taha, G.: Validation of ozone profiles retrieved from Stratospheric Aerosol and Gas Experiment III limb scatter measurements, J. Geophys. Res., 112, D13309, https://doi.org/10.1029/2006JD007679, 2007.

Rault, D. F. and Loughman, R. P.: The OMPS Limb Profiler Environmental Data Record algorithm theoretical basis document and expected performance, IEEE Trans. Geosci. Remote Sens., 51, 2505-2527, 2013.

Rieger, L., Bourassa A., and Degenstein D.: Merging the OSIRIS and sage II stratospheric aerosol records, J. Geophys. ResAtmos, 120, 8890-8904, 2015.

Rieger, L. A., Malinina, E. P., Rozanov, A. V., Burrows, J. P., Bourassa, A. E., and Degenstein, D. A.: A study of the approaches used to retrieve aerosol extinction, as applied to limb observations made by OSIRIS and SCIAMACHY, Atmos. Meas. Tech., 11, 3433-3445, https://doi.org/10.5194/amt11-3433-2018, 2018.

Rieger, L. A., Zawada, D. J., Bourassa, A. E., and Degenstein, D. A.: A multi-wavelength retrieval approach for improved OSIRIS aerosol extinction retrievals, J. Geophys. Res.-Atmos., 124, 7286-7307, https://doi.org/10.1029/2018JD029897, 2019.

Robock, A.: Volcanic eruptions and climate, Rev. Geophys., 38, 191-219, https://doi.org/10.1029/1998RG000054, 2000.

Robock, A. and Mao J.: The volcanic signal in surface temperature observations, J. Clim., 8, 1086-1103, https://doi.org/10.1175/15200442(1995)008<1086:TVSIST>2.0.CO;2, 1995.

Roth, C.: OSIRIS on ODIN, available at: https://research-groups. usask.ca/osiris/data-products.php\#Download, last access: August 2020 .

SAGE III ATBD: SAGE III Algorithm Theoretical Basis Document: Solar and Lunar Algorithm, Earth Observing System Project science Office, available at: https://eospso.gsfc.nasa.gov/ sites/default/files/atbd/atbd-sage-solar-lunar.pdf (last access: 5 February 2021), 2002.

Saitoh, N., Hayashida, S., Sugita, T., Nakajima, H., Yokota, T.,Hayashi, M., Shiraishi, K., Kanzawa, H., Ejiri, M. K., Irie,
H.,Tanaka, T., Terao, Y., Bevilacqua, R. M., Randall, C. E., Thomason, L. W., Taha, G., Kobayashi, H., and Sasano, Y.: Intercomparison of ILAS-II version 1.4 aerosol extinction coefficient at $780 \mathrm{~nm}$ with SAGE II, SAGE III, and POAM III, J. Geophys. Res., 111, D11S05, https://doi.org/10.1029/2005JD006315, 2006

Santer, B. D., Bonfils, C., Painter, J. F., Zelinka, M. D., Mears, C., Solomon, S., Schmidt, G. A., Fyfe, J. C., Cole, J. N. S., Nazarenko, L., Taylor, K. E., and Wentz, F. J.: Volcanic contribution to decadal changes in tropospheric temperature, Nat. Geosci., 7, 185-189, https://doi.org/10.1038/ngeo2098, 2014.

Schmidt, G. A., Shindell, D. T., and Tsigaridis, K.: Reconciling warming trends, Nat. Geosci., 7, 158-160, 2014.

Sioris, C. E., Boone C. D., Bernath P. F., Zou J., McElroy C. T., and McLinden C. A.: Atmospheric Chemistry Experiment (ACE) observations of aerosol in the upper troposphere and lower stratosphere from the Kasatochi volcanic eruption, J. Geophys. Res., 115, D00L14, https://doi.org/10.1029/2009JD013469, 2010.

Solomon, S.: Stratospheric ozone depletion: A review of concepts and theory, Rev. Geophys., 37, 275-316, 1999.

Solomon, S., Daniel, J. S., Neely III, R. R., Vernier, J.-P., Dutton, E. G., and Thomason, L. W.: The persistently variable "background" stratospheric aerosol layer and global climate change, Science, 333, 866-870, 2011.

SPARC: SPARC Assessment of Stratospheric Aerosol Properties (ASAP), Thomason, L. and Peter, Th. (Eds.), SPARC Report no. 4, WCRP-124, WMO/TD no. 1295, 2006.

Taha, G.: OMPS-NPP L2 LP Aerosol Extinction Vertical Profile swath daily 3slit V2, Greenbelt, MD, USA, Goddard Earth Sciences Data and Information Services Center (GES DISC), https://doi.org/10.5067/CX2B9NW6FI27, 2020.

Taha, G., Rault, D. F., Loughman, R. P., Bourassa, A. E., and von Savigny, C.: SCIAMACHY stratospheric aerosol extinction profile retrieval using the OMPS/LP algorithm, Atmos. Meas. Tech., 4, 547-556, https://doi.org/10.5194/amt-4-547-2011, 2011.

Thomason, L. W. and Poole, L. R.: Use of stratospheric aerosol properties as diagnostics of Antarctic vortex processes, J. Geophys. Res., 98, 23003-23012, 1993.

Thomason, L. W. and Taha, G.: SAGE III Aerosol Extinction Measurements: Initial Results, Geophys. Res. Lett., 30, 1631, https://doi.org/10.1029/2003GL017317, 2003.

Thomason, L. W. and Vernier, J.-P.: Improved SAGE II cloud/aerosol categorization and observations of the Asian tropopause aerosol layer: 1989-2005, Atmos. Chem. Phys., 13, 4605-4616, https://doi.org/10.5194/acp-13-4605-2013, 2013.

Thomason, L. W., Pitts, M. C., and Winker, D. M.: CALIPSO observations of stratospheric aerosols: a preliminary assessment, Atmos. Chem. Phys., 7, 5283-5290, https://doi.org/10.5194/acp-75283-2007, 2007a.

Thomason, L. W., Poole, L. R., and Randall, C. E.: SAGE III aerosol extinction validation in the Arctic winter: comparisons with SAGE II and POAM III, Atmos. Chem. Phys., 7, 14231433, https://doi.org/10.5194/acp-7-1423-2007, 2007 b.

Thomason, L. W., Moore, J. R., Pitts, M. C., Zawodny, J. M., and Chiou, E. W.: An evaluation of the SAGE III version 4 aerosol extinction coefficient and water vapor data products, Atmos. Chem. Phys., 10, 2159-2173, https://doi.org/10.5194/acp10-2159-2010, 2010. 
Thomason, L. W., Ernest, N., Millán, L., Rieger, L., Bourassa, A., Vernier, J.-P., Manney, G., Luo, B., Arfeuille, F., and Peter, T.: A global space-based stratospheric aerosol climatology: 1979-2016, Earth Syst. Sci. Data, 10, 469-492, https://doi.org/10.5194/essd-10-469-2018, 2018.

Thomason, L. W., Kovilakam, M., Schmidt, A., von Savigny, C., Knepp, T., and Rieger, L.: Evidence for the predictability of changes in the stratospheric aerosol size following volcanic eruptions of diverse magnitudes using space-based instruments, Atmos. Chem. Phys., 21, 1143-1158, https://doi.org/10.5194/acp21-1143-2021, 2021.

Torres, O., Bhartia, P. K., Taha, G., Jethva, H., Das, S., Colarco, P., Krotkov N., Omar A., Ahn C.: Stratospheric Injection of Massive Smoke Plume from Canadian Boreal Fires in 2017 as seen by DSCOVR-EPIC, CALIOP and OMPS-LP Observations, J. Geophys. Res.-Atmos., Atmospheres, 125, e2020JD032579, https://doi.org/10.1029/2020JD032579, 2020.

Trepte, C. R. and Hitchman M. H.: Tropical stratospheric circulation deduced from satellite aerosol data, Nature, 355, 626-628, https://doi.org/10.1038/355626a0, 1992.

Vanhellemont, F., Fussen, D., Mateshvili, N., Tétard, C., Bingen, C., Dekemper, E., Loodts, N., Kyr"ol"a, E., Sofieva, V., Tamminen, J., Hauchecorne, A., Bertaux, J.-L., Dalaudier, F., Blanot, L., Fanton d'Andon, O., Barrot, G., Guirlet, M., Fehr, T., and Saavedra, L.: Optical extinction by upper tropospheric/stratospheric aerosols and clouds: GOMOS observations for the period 2002-2008, Atmos. Chem. Phys., 10, 7997-8009, https://doi.org/10.5194/acp-10-7997-2010, 2010.

Vernier, J. P., Pommereau, J. P., Garnier, A., Pelon, J., Larsen, N., Nielsen, J., Christensen, T., Cairo, F., Thomason, L. W., Leblanc, T., and McDermid, I. S.: Tropical stratospheric aerosol layer from CALIPSO lidar observations, J. Geophys. Res., 114, D00H10, https://doi.org/10.1029/2009JD011946, 2009.

Vernier, J.-P., Thomason, L. W., and Kar, J.: CALIPSO detection of an Asian tropopause aerosol layer, Geophys. Res. Lett., 38, L07804, https://doi.org/10.1029/2010GL046614, 2011a.

Vernier, J.-P., Thomason, L. W., Pommereau, J.-P., Bourassa, A., Pelon, J., Garnier, A., Hauchecorne, A., Blanot, L., Trepte, C., Degenstein, D., and Vargas, F.: Major influence of tropical volcanic eruptions on the stratospheric aerosol layer during the last decade, Geophys. Res. Lett., 38, L12807, https://doi.org/10.1029/2011GL047563, 2011 b.

von Savigny, C., Ernst, F., Rozanov, A., Hommel, R., Eichmann, K.U., Rozanov, V., Burrows, J. P., and Thomason, L. W.: Improved stratospheric aerosol extinction profiles from SCIAMACHY: validation and sample results, Atmos. Meas. Tech., 8, 5223-5235, https://doi.org/10.5194/amt-8-5223-2015, 2015.
Wang, H., Damadeo, R., Flittner, D., Kramarova, N., Taha, G., Davis, S., Thompson, A., Strahan, S., Wang, Y., Froidevaux, L., Degenstein, D., Bourassa, A., Steinbrecht, W., Walker, K., Querel, R., Leblanc, T., Godin-Beekmann, S., Hurst, D., and Hall, E.: Validation of SAGE III/ISS Solar Ozone Data with Correlative Satellite and Ground Based Measurements, J. Geophys. Res.-Atmos., 125, e2020JD032430, https://doi.org/10.1029/2020JD032430, 2020.

Wang, P. H., Kent, G. S., McCormick, M. P., Thomason, L. W., and Yue, G. K.: Retrieval analysis of aerosol size distribution with simulated extinction measurements at SAGE III wavelengths, Appl. Opt., 35, 433-440, 1996.

Winker, D. M., Pelon, J., Coakley Jr., J. A., Ackerman, S. A., Charlson, R. J., Colarco, P. R., Flamant, P., Fu, Q., Hoff, R., Kittaka, C., Kubar, T. L., Le Treut, H., McCormick, M. P., Mégie, G., Poole, L., Powell, K., Trepte, C., Vaughan, M. A., and Wielicki, B. A.: The CALIPSO Mission: A Global 3D View Of Aerosols And Clouds, B. Am. Meteorol. Soc., 91, 1211-1229, https://doi.org/10.1175/2010BAMS3009.1, 2010.

Yu, P., Toon, O. B., Bardeen, C. G., Zhu, Y., Rosenlof, K. H., Portmann, R. W., Thornberry, T. D., Gao, R., Davis, S. M., Wolf, E. T., de Gouw, J., Peterson, D. A., Fromm, M. D., and Robock, A.: Black carbon lofts wildfire smoke high into the stratosphere to form a persistent plume, Science, 365, 587-590, https://doi.org/10.1126/science.aax1748, 2019.

Yue, G. K. and Deepak, A.: Retrieval of stratospheric aerosol size distribution from atmospheric extinction of solar radiation at two wavelengths, Appl. Opt., 22, 1639-1645, 1983.

Zawada, D., Franssens, G., Loughman, R., Mikkonen, A., Rozanov, A., Emde, C., Bourassa, A., Dueck, S., Lindqvist, H., Ramon, D., Rozanov, V., Dekemper, E., Kyrölä, E., Burrows, J. P., Fussen, D., and Degenstein, D.: Systematic Comparison of Vectorial Spherical Radiative Transfer Models in Limb Scattering Geometry, Atmos. Meas. Tech. Discuss. [preprint], https://doi.org/10.5194/amt-2020-470, in review, 2021.

Zhu, Y., Toon, O. B., Kinnison, D., Harvey, V. L., Mills, M. J., Bardeen, C. G., Pitts, M., Bègue, N., Renard, J. B., Berthet, G., and Jégou, F.: Stratospheric Aerosols, Polar Stratospheric Clouds, and Polar Ozone Depletion After the Mount Calbuco Eruption in 2015, J. Geophys. Res.-Atmos., 123, 12-308, 2018. 